\title{
Ação antrópica e resultantes sobre a estrutura e composição da Mata Atlântica na Ilha Grande, $\mathbf{R} \mathbf{J}^{1}$
}

\author{
Rogério Ribeiro de Oliveira²
}

\begin{abstract}
RESUMO
A Floresta Ombrófila Densa na Ilha Grande (RJ) é constituída por um mosaico de florestas secundárias de diferentes idades. Foram estudados trechos de florestas utilizados anteriormente para cultivos de subsistência de populações caiçaras a 5,25 e 50 anos. Para comparação, utilizou-se um trato de floresta primária. Nas áreas estudadas foi encontrado um total de 26 espécies na área de 5 anos, 70 na de 25 anos, 63 na de 50 anos e 134 na climáxica e a área basal foi de 5,6; 26,3; 32,4 e 57,9 m²/ha, respectivamente. A distribuição das espécies pelos grupos ecológicos permitiu a separação em 3 situações: a) com dominância de pioneiras (a área de 5 anos); b) com dominância das secundárias iniciais e tardias (as áreas de 25 e 50 anos) e c) com dominância das espécies climáxicas (a área climáxica). Os valores dos índices de Shannon foram de 2,51; 3,33; 3,10 e 4,28 nats/ind., para as mesmas. A participação das 10 espécies com maior Valor de Importância na densidade, freqüência e dominância tende a reduzir no sentido 5 anos-clímax. Em função da lenta evolução das variáveis estruturais nas áreas de 25 e 50 anos, estas foram classificadas como de clímax antrópico.

Palavras-chave: Mata Atlântica, Ilha Grande, caiçaras, fitossociologia.
\end{abstract}

\begin{abstract}
The Atlantic Rain Forest at Ilha Grande is constituted by a mosaic of different aged forests. I examined a successional gradient of 5-yr, 25-yr and 50-yr-old slope forests, growing in areas once used for subsistence agriculture by the caiçara people in what is today the Praia do Sul State Biological Reserve on Ilha Grande, Rio de Janeiro state. These areas were compared to a near-climax forest tract located in Ilha Grande State Park. There were 26 species in the 5-yr-old forest and a total basal area of $5.6 \mathrm{~m}^{2} / \mathrm{ha}$; the 25 -yr and 50-yr-old forests and the climax forest had 70 species, $26.3 \mathrm{~m} 2 / \mathrm{ha} ; 63$ species, $32.4 \mathrm{~m}^{2} /$ ha; and 134 species, $57.9 \mathrm{~m}^{2} /$ ha, respectively. Species percentage distribution in ecological groups showed three distinct scenarios: a) dominance of pioneers (5-yr forest); b) dominance of early and late secondary species (25-yr and 50-yr-old forests); and c) dominance of climax species (climax forest). Shannon's Diversity Index for the four areas was 2.51, 3.33, 3.10 and 4.28 nats/ind. The 10 top species according to Importance Value decreased in percentage of total density, frequency and dominance from the 5-yr to the climax forest. The 25-yr and 50-yr-old forests were classified as manmade climax forests because the patterns studied evolved slowly.
\end{abstract}

Key words: Atlantic Rain Forest, Ilha Grande, caiçaras, phytosociology, ecological succession.

\section{INTRODUÇÃO}

Em uma perspectiva histórica, é evidente que o legado ambiental que nos chegou até hoje é produto das relações de populações passadas com o meio. Assim, em termos de paisagem, o que temos hoje por "natural" pode se tratar, na verdade, de um sistema manejado durante séculos. Pesquisas recentes (Hecht \& Posey, 1989; Gadgil et al., 1993 e Adams, 2000) mostram a

${ }^{1}$ Parte da tese de Doutorado apresentada ao Programa de Pós-graduação em Geografia da UFRJ sob a orientação da Dra. Ana Luíza Coelho Netto.

${ }^{2}$ Prof. Assistente do Depto. de Geografia e Meio Ambiente, PUC-Rio. Rua Marquês de São Vicente, 255. CEP $22453-900$. e-mail: machline@openlink.com.br.CNPq. 
importância do conhecimento de populações tradicionais e, ainda, de como estes povos vêm manejando o meio ambiente por meio de suas práticas agrícolas, desde tempos imemoriais.

A ocupação humana na Ilha Grande (localizada no litoral sul do estado do Rio de Janeiro) teve início há mais de 3.000 anos com bandos de coletores-caçadores que chegaram a formar sambaquis em numerosos pontos. A substituição destes grupamentos por grupos indígenas de outras culturas (guianazes e tupinambás) trouxe como principal alteração geoecológica o aparecimento da agricultura feita com o uso do fogo, que seria retomada séculos mais tarde pelos caiçaras. A partir do século XVIII, começaram a se estabelecer em alguns pontos da Ilha Grande fazendas de cana e café (Mello, 1987; Tenório, 1999).

No entanto, com relação ao impacto de culturas sobre a paisagem, é de se destacar a presença dos caiçaras na Ilha Grande. A cultura caiçara é característica do litoral do estados do Rio de Janeiro, São Paulo e Paraná, e é baseada na pesca e em roças de subsistência. O sistema de plantio utilizado pelos caiçaras, chamado de roça de toco ou coivara, é conhecido de longa data no interior do país, tratandose de uma herança indígena. Este método de plantio é baseado na derrubada e queima da mata, seguindo-se um período de abandono ou pousio para restauração da fertilidade do solo, que pode variar de 4 até 50 anos (Schmidt, 1958; Adams, 2000). Com relação à sua sustentabilidade, Silva (1998) realizou uma roça caiçara experimental na Reserva Biológica Estadual da Praia do Sul (Ilha Grande), onde evidenciou diversos aspectos positivos ligados à sua sustentabilidade ecológica. Quanto ao impacto deste tipo de cultura sobre a paisagem, Ewel (1976) destaca que a restauração da fertilidade que ocorre no período de pousio é feita, em grande parte, pelo retorno da matéria orgânica e de nutrientes para a superfície do solo, via produção e subseqüente decomposição da serapilheira. Whitmore (1990) afirma que a agricultura de subsistência permite um máximo de 10 a 20 pessoas $/ \mathrm{km}^{2}$, pois, a qualquer tem- po, apenas $10 \%$ da área pode estar sob cultivo, em decorrência da necessidade de terras em pousio (repouso para recuperação da fertilidade do solo). As roças caiçaras têm em média 0,38 ha, são cultivadas por 2,8 anos e deixadas em pousio por 9,7 anos (Adams, 2000). No caso particular da Vila do Aventureiro, o tempo médio de cultivo é de 3,7 anos, e o de pousio 4,8 anos (Toffoli \& Oliveira, 1996).

A maior parte do território da Ilha Grande é constituída por grandes extensões de formações secundárias, a maioria em estágios avançados de regeneração, cujas idades encontram-se na faixa de 30 a 100 anos. Próximo aos pequenos povoados são encontradas capoeiras mais recentes (entre 5 e 25 anos). No presente trabalho, pretende-se examinar a resultante das roças caiçaras sobre a composição e estrutura do processo sucessional da Floresta Atlântica na Ilha Grande.

\section{MATERIAIS E MÉTODOS}

Área de estudo: A Ilha Grande faz parte de um conjunto de ilhas que caracterizam uma baía de mesmo nome, no município de Angra dos Reis, no litoral sul do Estado do Rio de Janeiro. Trata-se de um fragmento do maciço litorâneo de cerca de $190 \mathrm{~km}^{2}$, com um relevo bastante acidentado, sendo o Pico do Papagaio $(959 \mathrm{~m})$ e a Serra do Retiro $(1.031 \mathrm{~m})$ seus pontos de destaque. De acordo com Veloso et al. (1991), a Ilha Grande situa-se no domínio da Floresta Ombrófila Densa.

Foram delimitadas, na mata de encosta da Reserva Biológica Estadual da Praia do Sul (RBEPS), com o auxílio de moradores mais antigos, três formações, com as idades de 5, 25 e 50 anos (Fig. 1). A primeira está localizada na Vila do Aventureiro, próxima às roças dos moradores. Como forma de comparação, foi utilizado um trecho de floresta com características climáxicas (ou seja, sem qualquer vestígio de utilização anterior), situado no Parque Estadual da Ilha Grande e corresponde à floresta com máximo desenvolvimento presente na ilha. Informações sobre solos das quatro áreas encontram-se em Oliveira (1999). 


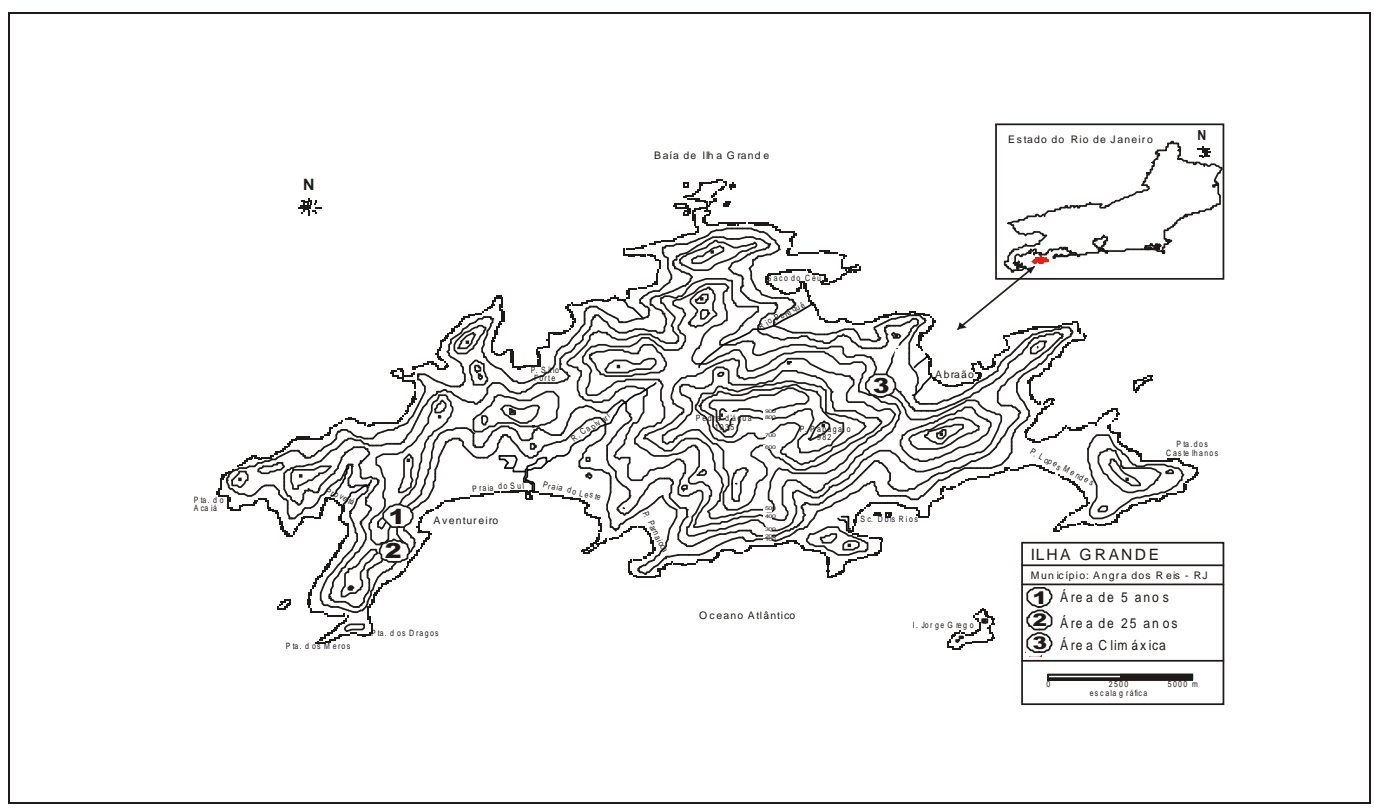

Figura 1 - Localização das áreas de estudo na Ilha Grande, RJ.

As características gerais de cada área encontram-se a seguir:

Tabela 1 - Características geográficas das parcelas de estudos (RBEPS: Reserva Biológica Estadual da Praia do Sul; PEIG: Parque Estadual da Ilha Grande)

\begin{tabular}{|c|c|c|c|c|c|}
\hline Idade & $\begin{array}{c}\text { Nome } \\
\text { da localidade }\end{array}$ & Posição & $\begin{array}{l}\text { Altitude } \\
(\text { m.s.m) }\end{array}$ & $\begin{array}{l}\text { Declividade } \\
\text { (graus) }\end{array}$ & $\begin{array}{l}\text { Orientação } \\
\text { da encosta }\end{array}$ \\
\hline 5 anos & $\begin{array}{l}\text { Vila do Aventureiro } \\
\text { (RBEPS) }\end{array}$ & $\begin{array}{l}23^{\circ} 11^{\prime} 46^{\prime \prime} \mathrm{S} \\
44^{\circ} 19^{\prime} 26^{\prime \prime} \mathrm{W}\end{array}$ & 80 & 23 & SE \\
\hline 25 anos & $\begin{array}{l}\text { Simão Dias } \\
\text { (RBEPS) }\end{array}$ & $\begin{array}{l}23^{\circ} 11^{\prime} 24^{\prime \prime} \mathrm{S} \\
44^{\circ} 19^{\prime} 40^{\prime \prime} \mathrm{W}\end{array}$ & 140 & 22 & $S$ \\
\hline 50 anos & $\begin{array}{l}\text { Sertão das Águas Lindas } \\
\text { (RBEPS) }\end{array}$ & $\begin{array}{l}23^{\circ} 09^{\prime} 25^{\prime \prime} \mathrm{S} \\
44^{\circ} 10^{\prime} 67^{\prime \prime} \mathrm{W}\end{array}$ & 260 & 20 & SW \\
\hline climáxica & $\begin{array}{l}\text { Pico do Papagaio } \\
\text { (PEIG) }\end{array}$ & $\begin{array}{l}23^{\circ} 08^{\prime} 87^{\prime \prime} \mathrm{S} \\
44^{\circ} 11^{\prime} 06^{\prime \prime} \mathrm{W}\end{array}$ & 280 & 25 & SE \\
\hline
\end{tabular}

Estrutura e composição da vegetação: A estrutura fitossociológica das 4 áreas supracitadas foi determinada com o uso em cada uma de 26 parcelas de $10 \mathrm{~m}$ de lado $\left(100 \mathrm{~m}^{2}\right)$. A marcação das parcelas de 5, 25 e 50 anos em campo foi acompanhada por moradores que haviam efetivamente utilizado estas áreas com antigas roças e que confirmaram tanto a idade quanto o seu perímetro exato. As parcelas foram estabelecidas a partir do centro de cada antiga roça abandonada e foi respeitada uma faixa externa visando minimizar efeitos de borda. No sentido de padronizar as áreas de estudo para fins de comparação, a área total de cada estágio estudado foi definida a partir da menor área que se dispunha $\left(2.600 \mathrm{~m}^{2}\right)$. Em cada área foram coletados todos os indivíduos com altura superior a $2 \mathrm{~m}$ e dap (diâmetro à altura do peito) superior a $2,5 \mathrm{~cm}$, incluindo os fetos arborescentes e palmeiras e excluindo-se as lianas. 
O material botânico foi identificado através de consulta bibliográfica, comparação em herbário e, quando possível, com auxílio de especialistas. As exsicatas encontram-se incorporadas ao acervo do Herbário Alberto Castellanos (GUA), do Serviço de Ecologia Aplicada da Fundação de Engenharia do Meio Ambiente e do Herbarium Friburgense (FCAB), da Pontifícia Universidade Católica do Rio de Janeiro. No caso da área de 25 anos, foi utilizado o inventário feito nesta mesma área por Delamonica (1997).

A análise fitossociológica foi feita empregando-se as fórmulas apresentadas por MuellerDombois \& Ellenberg (1974) para densidade, frequiência e dominância e valor de importância (VI). A estimativa da diversidade foi obtida utilizando-se o índice de diversidade de Shannon (Magurran, 1988). Para a análise de similaridade entre os trechos de floresta estudados e outros da floresta atlântica da região Sudeste, utilizou-se o índice de Sorensen (MuellerDombois \& Ellenberg, 1974).

A classificação sucessional das espécies em grupos ecológicos foi elaborada preliminarmente com base em diversos autores que utilizaram esta abordagem em seus levanta- mentos (Leitão Filho, 1993; Roizman, 1993 e Costa \& Mantovani, 1995). Como ocorrem constantes discrepâncias na classificação de uma mesma espécie, a lista foi revista com base em observações de campo e na presença/ ausência das espécies nos estágios sucessionais estudados.

\section{RESULTADOS E DISCUSSÃO}

Aspectos florísticos: No inventário das 4 áreas de estudo foram amostrados 2.332 indivíduos distribuídos em 236 espécies, 122 gêneros e 60 famílias, em uma área total de $10.400 \mathrm{~m}^{2}$ (1,04ha). A Tabela 2 apresenta as principais características da flora das áreas amostradas. Foram encontradas 26 espécies na área de 5 anos, 70 na de 25 anos, 63 na de 50 anos e 134 na área climáxica, representando uma diversidade média de respectivamente 1,$0 ; 2,7 ; 2,4$ e 5,1 espécies/ $100 \mathrm{~m}^{2}$. Em termos de espécies de ocorrência exclusiva em cada área sucessional estudada, o maior percentual encontrado foi na área climáxica $(82 \%)$, seguida pela de 50 anos (55\%). As áreas de 5 e 25 anos apresentaram $42 \%$ e $46 \%$, respectivamente.

Tabela 2 - Principais características da flora do gradiente sucessional estudado na Ilha Grande, RJ

\begin{tabular}{lllll}
\hline características & $\mathbf{5}$ anos & $\mathbf{2 5}$ anos & $\mathbf{5 0}$ anos & climáxica \\
\hline & & & & \\
número de espécies & 26 & 70 & 63 & 134 \\
espécies exclusivas & $11(42 \%)$ & $32(46 \%)$ & $35(55 \%)$ & $110(82 \%)$ \\
número de espécies/100m ${ }^{2}$ & 1,0 & 2,7 & 2,4 & 5,1 \\
número de famílias & 17 & 29 & 29 & 41 \\
Índice de Sorensen: & - & $25,0 \%$ & $17,9 \%$ & $2,5 \%$ \\
área de 5 anos & & - & $27,1 \%$ & $13,7 \%$ \\
área de 25 anos & & & - & $10,2 \%$ \\
área de 50 anos & & & & \\
\end{tabular}

Um problema sério para a comparação de inventários florísticos é o das diferenças metodológicas. Embora o número de espécies encontrado na área climáxica do presente estudo aproxime-se de outros levantamentos feitos em florestas conservadas (Tab. 3), algumas ressalvas devem ser feitas. Em termos de número absoluto de espécies, valores mais elevados foram encontrados por Peixoto \& Gentry (1990) na mata de tabuleiro do Espírito Santo (216 espécies). Neste caso, o 
elevado número de espécies pode ser creditado ao fato de que a mata de tabuleiro é considerada uma vegetação de transição que incorpora elementos das florestas atlântica e amazônica, o que constitui um dos motivos para o alto número de espécies observado. Diferencia-se este estudo do presente o fato de que os autores amostraram também as lianas. No entanto, embora as metodologias sejam diversas e as áreas amostradas de diferentes tamanhos, o número de espécies encontradas no Pico do Papagaio (área climáxica) - 134 - pode ser considerado relativamente elevado, levando-se em consideração a área amostrada $\left(2.600 \mathrm{~m}^{2}\right)$. No vale do Rio Pilões $(\mathrm{Cu}-$ batão, SP), Leitão Filho et al. (1993) encontrou 145 espécies em $4.000 \mathrm{~m}^{2}$ e Guedes-Bruni et al. (1997), usando critério de inclusão igual ao nosso, encontrou 189 espécies em 1ha de mata também conservada, em Macaé de Cima (RJ).

$\mathrm{O}$ incremento do número de espécies entre a área de 5 e a de 25 anos foi de 2,7 vezes, ao passo que entre esta e a de 50 anos houve uma redução de $10 \%$. O aumento de espécies verificado entre a área de 50 anos e a climáxica foi da ordem de 2,1 vezes. A densidade de espécies reduziu de 2,7 para 2,4 espécies $/ 100 \mathrm{~m}^{2}$ entre as áreas de 25 e 50 anos. A redução de espécies observada entre estas duas áreas constitui algo fora do padrão teórico esperado, pelo fato de ser o aumento do número de espécies ao longo do tempo sucessional uma das características gerais da sucessão ecológica (Clements, 1916; Horn, 1974). A modificação da sucessão pode ocorrer em função de fatores como a disponibilidade de propágulos na área (efeito da paisagem), o histórico e os níveis de perturbação na área e os efeitos das interações entre as espécies (Finegan, 1996). Assim, o número maior de espécies detectado na área de 25 anos em relação à de 50 anos pode, entre outros fatores, dever-se ao fato de que este estágio encontra-se em um quadro intermediário, que incorpora um número maior de pioneiras e secundárias iniciais, como pode ser visto na Tab. 3. Poder-se-iam também apontar os critérios de inclusão aqui utilizados como uma das causas da redução do número de espécies entre as áreas de 25 e 50 anos, pois podem estar sendo amostrados elementos do sub-bosque, plântulas e pioneiras que assumem populações próprias em cada sere. Esta flutuação no número total de espécies entre cada área estudada evidencia aspectos não lineares do processo sucessional. Crow (1980) destaca a existência de espécies que ao longo de um processo sucessional apresentam ciclos de vida efêmeros, podendo passar de membros proeminentes na comunidade a baixos níveis de abundância ou mesmo desaparecer. Segundo autores como Saldarriaga \& Uhl (1991), a visão moderna sobre sucessão não aceita a idéia de uma estabilidade de sítio a longo prazo ou a existência de um ponto final para este processo. Enfatiza-se a importância de perturbações freqüentes (como o surgimento de clareiras naturais), além de se assumir que as mudanças contínuas na vegetação são a norma e não a exceção. A variabilidade de processos envolvidos na sucessão pode ser ilustrada pelo fato de Saldarriaga \& Uhl (1991) terem encontrado, em estandes de 70 anos na Amazônia peruana, um número de espécies próximo ao da floresta madura.

A entrada de espécies na área de 5 anos é tipicamente por rebrota de tocos, já que durante o período de implantação da roça caiçara, estes são mantidos vivos e fisiologicamente atuantes, constituindo a fonte inicial de colonização do sítio (Oliveira et al., 1994). Por ocasião do abandono da roça, a rebrota é imediata e vigorosa. Ulh et al. (1988) verificaram que em regiões com uso leve, a rebrota a partir de tocos e estolões é intensa, sendo a principal fonte de entrada de espécies no processo de regeneração da área. Segundo eles, a perturbação gerada pela criação de pastos, por exemplo, tem um efeito muito maior e mais prolongado sobre o processo sucessional do que a agricultura de subsistência tradicional. Baider $e t$ al. (2001) constataram que o banco de sementes de uma floresta de idade similar localizada em Paranapiacaba (SP) não apresentou nenhuma espécie envolvida na sua regeneração. Como cerca de $90 \%$ das espécies da área de 5 anos surgiu por rebrota e não por recruta- 
mento do banco de sementes do solo, concluise que este fator inicial interfere diretamente na composição da guilda das espécies pioneiras e colonizadoras. Em um recorte temporal e espacial mais amplo, pode-se considerar, portanto, a cultura caiçara responsável pela seleção de espécies e de tipos ecológicos especializados na ocupação de espaços abertos, ou seja, pelo conjunto de espécies pioneiras e secundárias iniciais disponível em seu território.

O índice de Sorensen leva em consideração as diferenças no número de espécies de áreas que se quer comparar. Segundo MuellerDombois \& Ellenberg (1974), duas comunidades podem ser consideradas floristicamente similares quando o índice de Sorensen for superior a 50\%, o que não foi o caso em nenhuma das áreas estudadas. Possivelmente, esta não similaridade entre as áreas se deve ao fato de ter sido amostrado em cada área um único estágio sucessional homogêneo em termos estruturais, estando as idades bem definidas. Ainda assim, a utilização deste índice mostrou que a similaridade florística entre as áreas de 5 e 25 anos $(25,0 \%)$ é próxima ao valor encontrado entre as áreas de 25 e 50 anos (27,1\%), suplantando bastante os valores encontrados entre a de 5 e 50 anos $(17,9 \%)$ e entre a de 25 anos e a climáxica $(13,7 \%)$ ou ainda entre a de 50 anos e a climáxica (10,2\%). Como seria razoável de se esperar, a similaridade entre os extremos - a área de 5 anos e a climáxica - foi a mais baixa: $2,5 \%$. Em outras palavras, a similaridade entre as áreas de 5, 25 e 50 anos é significativamente maior do que a de qualquer destas com a área climáxica.

A Tab. 3 apresenta todas as espécies encontradas, ordenadas por família e suas respectivas classificações sucessionais. A única espécie que ocorreu nas quatro áreas de estudo foi Lamanonia ternata. Com ocorrência nas áreas de 5 anos, 25 anos e 50 anos tivemos Tabernaeontana laeta, Ilex integerrima, Casearia sylvestris, Miconia cinnamomifolia e Cabralea cangerana. Já Hieronyma alchorneoides foi a única que ocorreu simultaneamente nas áreas de 25 anos, 50 anos e climáxica.

Tabela 3 - Relação das espécies das quatro áreas de estudo, sua ocorrência e classificação sucessional (pi = pioneira; si = secundária inicial; $\mathrm{st}=$ secundária tardia; $\mathrm{cl}=$ climáxica e s/d = sem dados)

\begin{tabular}{|c|c|c|c|c|c|c|}
\hline família & espécie & $\begin{array}{c}5 \\
\text { anos }\end{array}$ & $\begin{array}{c}25 \\
\text { anos }\end{array}$ & $\begin{array}{c}\mathbf{5 0} \\
\text { anos }\end{array}$ & clímax & $\begin{array}{r}\text { grupo } \\
\text { ecológico }\end{array}$ \\
\hline Anacardiaceae & Tapirira guianensis Aubl. & & & $*$ & & st \\
\hline \multirow[t]{8}{*}{ Annonaceae } & Annona sp. & & & $*$ & & $\mathrm{~s} / \mathrm{d}$ \\
\hline & $\begin{array}{l}\text { Guatteria latifolia (Mart. ) } \\
\text { R.E. Fries }\end{array}$ & & & * & & st \\
\hline & Guatteria sp. & & & $*$ & & s/d \\
\hline & $\begin{array}{l}\text { Rollinia dolabripetala } \\
\text { (Raddi) A. St. Hil. }\end{array}$ & & & $*$ & & si \\
\hline & Rollinia laurifolia Schlecht. & & & * & & st \\
\hline & $\begin{array}{l}\text { Oxandra martiana } \\
\text { (Schlecht.) R.E. Fries }\end{array}$ & & & & * & $\mathrm{cl}$ \\
\hline & Xylopia brasiliensis Spreng. & & & & * & si \\
\hline & $\begin{array}{l}\text { Xylopia langsdorffiana A. St. hil. } \\
\text { \& Tul ssp. lanceolata } \\
\text { (R.E. Fries) M.C. Dias }\end{array}$ & & & & $*$ & $\mathrm{cl}$ \\
\hline \multirow[t]{2}{*}{ Apocynaceae } & Tabernaeontana laeta Mart. & * & * & * & & si \\
\hline & Apocynaceae sp. & & & & $*$ & $\mathrm{~s} / \mathrm{d}$ \\
\hline Aquifoliaceae & Ilex integerrima Reiss. & * & * & * & & si \\
\hline
\end{tabular}




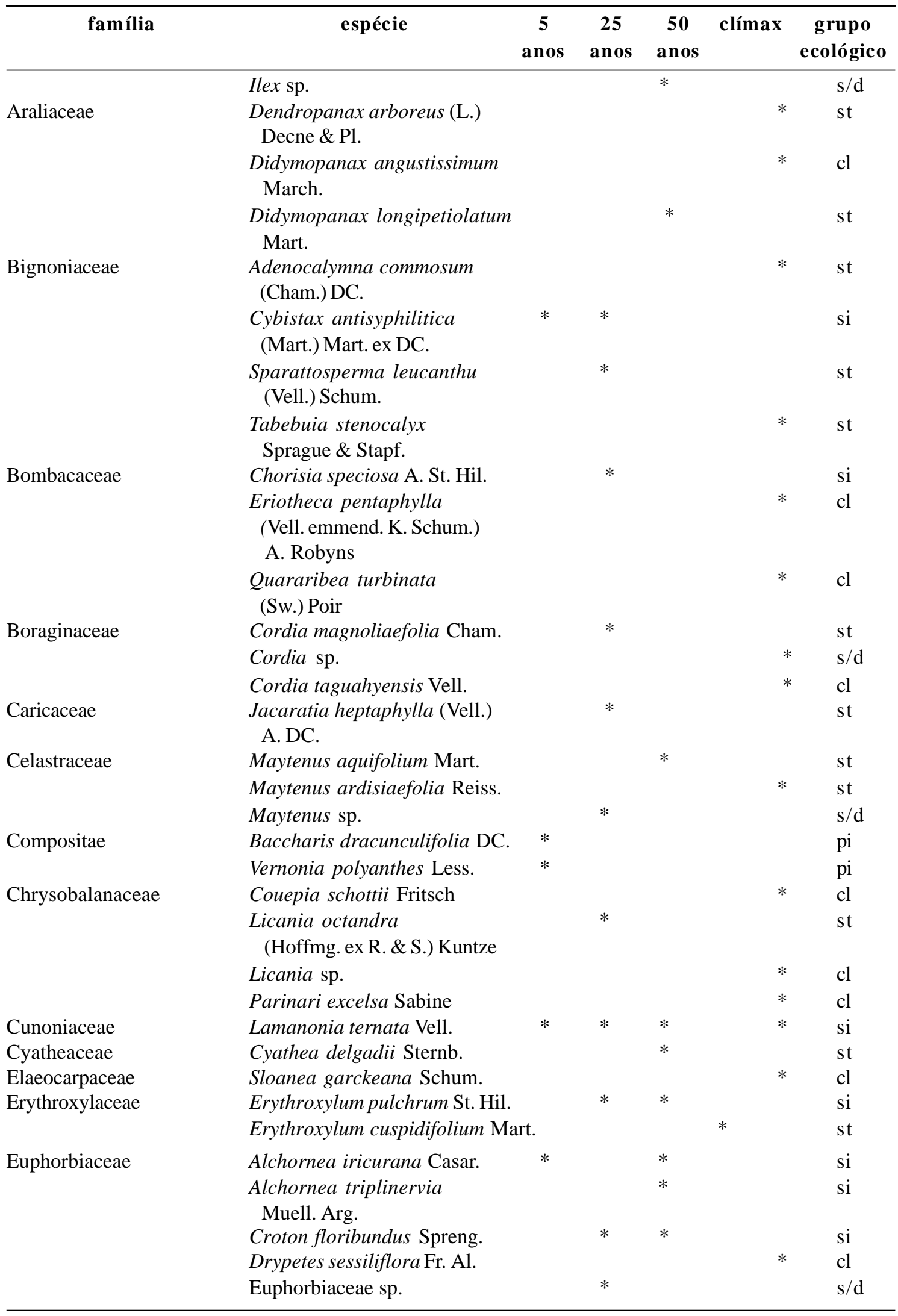

Rodriguésia 53 (82): 33-58. 2002 


\begin{tabular}{|c|c|c|c|c|c|c|}
\hline família & espécie & $\begin{array}{c}5 \\
\text { anos }\end{array}$ & $\begin{array}{c}25 \\
\text { anos }\end{array}$ & $\begin{array}{c}50 \\
\text { anos }\end{array}$ & clímax & $\begin{array}{r}\text { grupo } \\
\text { ecológico }\end{array}$ \\
\hline & $\begin{array}{l}\text { Hieronyma alchorneoides } \\
\text { Fr. Al. }\end{array}$ & & $*$ & $*$ & $*$ & $\mathrm{si}$ \\
\hline & $\begin{array}{l}\text { Mabea brasiliensis } \\
\text { Muell. Arg. }\end{array}$ & & & & $*$ & st \\
\hline & $\begin{array}{l}\text { Pausandra megalophylla } \\
\text { Muell. Arg. }\end{array}$ & & & & $*$ & $\mathrm{cl}$ \\
\hline & Pera glabrata (Schott) Baill. & & $*$ & & $*$ & st \\
\hline & Pera leandri Baill. & & & & $*$ & $\mathrm{cl}$ \\
\hline & $\begin{array}{l}\text { Sapium glandulatum } \\
\text { (Vell.) Pax }\end{array}$ & & $*$ & & & st \\
\hline & Senefeldera multiflora Mart. & & & & $*$ & $\mathrm{cl}$ \\
\hline & Tetraplandra leandrii Baillon & & & & $*$ & $\mathrm{cl}$ \\
\hline & Tetraplandra $\mathrm{sp}$ & & & & $*$ & $\mathrm{~s} / \mathrm{d}$ \\
\hline & $\begin{array}{l}\text { Tetrorchidium aff. } \\
\text { rubrivenium Poepp. \& Endl. }\end{array}$ & & & & $*$ & $\mathrm{cl}$ \\
\hline \multirow[t]{5}{*}{ Flacourtiaceae } & $\begin{array}{l}\text { Casearia commersoniana } \\
\text { Cambess. }\end{array}$ & & & $*$ & & st \\
\hline & Casearia decandra Jacq. & & $*$ & & & st \\
\hline & Casearia pauciflora Cambess. & & & $*$ & $*$ & st \\
\hline & Casearia sylvestris $\mathrm{Sw}$ & $*$ & $*$ & $*$ & & pi \\
\hline & Flacourtiaceae sp. & & $*$ & & & $\mathrm{~s} / \mathrm{d}$ \\
\hline \multirow[t]{5}{*}{ Guttiferae } & $\begin{array}{l}\text { Rheedia gardneriana } \\
\text { Triana \& Planch. }\end{array}$ & & $*$ & & & st \\
\hline & Guttiferae sp. & & & & $*$ & $\mathrm{~s} / \mathrm{d}$ \\
\hline & $\begin{array}{l}\text { Kielmeyera membranacea } \\
\text { Casar. }\end{array}$ & & & & $*$ & $\mathrm{cl}$ \\
\hline & Kielmeyera sp. & & & & $*$ & $\mathrm{cl}$ \\
\hline & $\begin{array}{l}\text { Rheedia brasiliensis } \\
\text { (Mart.) Pl. \& Tr. }\end{array}$ & & $*$ & & $*$ & st \\
\hline \multirow[t]{2}{*}{ Hippocrateaceae } & $\begin{array}{l}\text { Salacia elliptica } \\
\text { (Mart.) G. Don }\end{array}$ & & & & $*$ & $\mathrm{cl}$ \\
\hline & Salacia sp. & & & & $*$ & st \\
\hline \multirow[t]{12}{*}{ Lauraceae } & Aniba sp. & & & & $*$ & $\mathrm{~s} / \mathrm{d}$ \\
\hline & Aniba viridis $\mathrm{Mez}$ & & & & $*$ & $\mathrm{cl}$ \\
\hline & $\begin{array}{l}\text { Cryptocarya moschata } \\
\text { Nees \& Mart. ex Nees }\end{array}$ & & $*$ & & $*$ & st \\
\hline & $\begin{array}{l}\text { Nectandra membranacea } \\
\quad \text { (Sw.) Griseb }\end{array}$ & & $*$ & $*$ & & si \\
\hline & Nectandra sp. & & & $*$ & & $\mathrm{~s} / \mathrm{d}$ \\
\hline & $\begin{array}{l}\text { Ocotea diospyrifolia } \\
\text { (Meissn.) Mez }\end{array}$ & & $*$ & & $*$ & $\mathrm{cl}$ \\
\hline & Ocotea divaricata (Nees) Mez & & & & $*$ & $\mathrm{cl}$ \\
\hline & Ocotea glaziovii $\mathrm{Mez}$ & & $*$ & & $*$ & st \\
\hline & Ocotea schottii (Meissn.) Mez & & & & $*$ & $\mathrm{cl}$ \\
\hline & Ocotea sp. & & $*$ & & & $\mathrm{~s} / \mathrm{d}$ \\
\hline & Ocotea teleiandra (Nees) Mez & & & & $*$ & $\mathrm{cl}$ \\
\hline & Ocotea tenuiflora (Nees) Mart. & & $*$ & & & $\mathrm{cl}$ \\
\hline
\end{tabular}




\begin{tabular}{|c|c|c|c|c|c|c|}
\hline família & espécie & $\begin{array}{c}5 \\
\text { anos }\end{array}$ & $\begin{array}{c}25 \\
\text { anos }\end{array}$ & $\begin{array}{c}\mathbf{5 0} \\
\text { anos }\end{array}$ & clímax & $\begin{array}{c}\text { grupo } \\
\text { ecológico }\end{array}$ \\
\hline Lecythidaceae & $\begin{array}{l}\text { Cariniana estrellensis } \\
\text { (Raddi) Kuntze }\end{array}$ & & & & $*$ & $\mathrm{cl}$ \\
\hline \multirow[t]{17}{*}{ Leguminosae } & $\begin{array}{l}\text { Anadenanthera colubrina } \\
\text { (Vell.) Bren. }\end{array}$ & $*$ & $*$ & & & pi \\
\hline & Cpaifera trapezifolia Hayne & & & & $*$ & $\mathrm{cl}$ \\
\hline & Cpaifera lucens Dwryer & & & & * & $\mathrm{cl}$ \\
\hline & Inga edulis Mart & & & $*$ & & st \\
\hline & Inga lancifolia Benth. & & & & * & st \\
\hline & Inga marginata Willd. & & & $*$ & & si \\
\hline & Inga sp. & & & & $*$ & $\mathrm{~s} / \mathrm{d}$ \\
\hline & $\begin{array}{l}\text { Inga subnuda Salzm. ex Benth. } \\
\text { var. luschnathiana (Benth.) } \\
\text { T.D. Penn. }\end{array}$ & & & $*$ & & st \\
\hline & Inga striata Benth. & & $*$ & & & si \\
\hline & Inga tenuis (Vell.) Mart. & & & & * & $\mathrm{cl}$ \\
\hline & Machaerium sp. & $*$ & $*$ & & & si \\
\hline & Ormosia sp. & & & & * & $\mathrm{s} / \mathrm{d}$ \\
\hline & Pithecellobium sp. & & & & $*$ & s/d \\
\hline & $\begin{array}{l}\text { Pseudopiptadenia contorta } \\
\text { (DC.) G.P. Lewis \& M.P. Lima }\end{array}$ & & & & $*$ & st \\
\hline & $\begin{array}{l}\text { Schizolobium parahyba } \\
\text { (Vell.) Blake }\end{array}$ & $*$ & & & & pi \\
\hline & Sclerolobium glaziovii Taub. & & $*$ & $*$ & & st \\
\hline & Senna multijuga (Rich.) I.\& B. & $*$ & & $*$ & & pi \\
\hline Lythraceae & Lafoensia glyptocarpa Koehne & & & & * & $\mathrm{cl}$ \\
\hline Malpighiaceae & Byrsonima sericea DC. & $*$ & & & & pi \\
\hline \multirow[t]{8}{*}{ Melastomataceae } & $\begin{array}{l}\text { Miconia brasiliensis (Spreng.) } \\
\text { Triana }\end{array}$ & & $*$ & & & si \\
\hline & Miconia calvescens DC. & $*$ & & & & si \\
\hline & $\begin{array}{l}\text { Miconia cinnamomifolia } \\
\text { (DC.) Naud. }\end{array}$ & * & $*$ & $*$ & & pi \\
\hline & Miconia holoserica (L.) DC. & & $*$ & & & si \\
\hline & $\begin{array}{l}\text { Miconia mirabilis } \\
\text { (Aubl.) L. Wms. }\end{array}$ & & $*$ & & & si \\
\hline & Miconia prasina $(\mathrm{Sw}.) \mathrm{DC}$ & $*$ & $*$ & & & si \\
\hline & Tibouchina estrellensis Cogn. & $*$ & & & & $\mathrm{pi}$ \\
\hline & $\begin{array}{l}\text { Tibouchina granulosa } \\
\text { (Desr.) Cogn. }\end{array}$ & & * & & & pi \\
\hline \multirow[t]{8}{*}{ Meliaceae } & Cabralea canjerana (Vell.) Mart. & * & $*$ & $*$ & & st \\
\hline & Carapa guianensis Aubl. & & $*$ & $*$ & & st \\
\hline & Cedrela fissilis Vell. & & & * & & st \\
\hline & $\begin{array}{l}\text { Guarea macrophylla Vahl ssp. } \\
\text { tuberculata (Vell.) Penn. }\end{array}$ & & * & & * & si \\
\hline & Guarea sp. & & * & & & st \\
\hline & Trichilia casaretti L. DC. & & & * & & st \\
\hline & Trichilia elegans A. Juss. & & & $*$ & * & st \\
\hline & Trichilia hirta $\mathrm{L}$. & & $*$ & & * & st \\
\hline
\end{tabular}




\begin{tabular}{|c|c|c|c|c|c|c|}
\hline família & espécie & $\begin{array}{c}5 \\
\text { anos }\end{array}$ & $\begin{array}{c}25 \\
\text { anos }\end{array}$ & $\begin{array}{c}50 \\
\text { anos }\end{array}$ & clímax & $\begin{array}{r}\text { grupo } \\
\text { ecológico }\end{array}$ \\
\hline & Trichilia schumanniana Harms & & & & $*$ & st \\
\hline & Trichilia silvatica C. DC. & & & & $*$ & st \\
\hline & Trichilia sp. & & & $*$ & $*$ & st \\
\hline \multirow[t]{9}{*}{ Monimiaceae } & Mollinedia acutissima Perk. & & & $*$ & & $\mathrm{cl}$ \\
\hline & Mollinedia chrysolaeana Perk. & & & $*$ & & $\mathrm{cl}$ \\
\hline & Mollinedia longifolia Tulasne & & $*$ & & & st \\
\hline & Mollinedia oligantha Perk. & & $*$ & & $*$ & $\mathrm{cl}$ \\
\hline & Mollinedia pachysandra Perk. & & & & $*$ & $\mathrm{cl}$ \\
\hline & $\begin{array}{l}\text { Mollinedia schottiana } \\
\text { (Spreng.) Perk. }\end{array}$ & & & $*$ & $*$ & st \\
\hline & Monimiaceae sp. & & & $*$ & & $\mathrm{~s} / \mathrm{d}$ \\
\hline & Siparuna apiosyce A. DC. & & & $*$ & & pi \\
\hline & Siparuna arianae V. Pereira & $*$ & & & & pi \\
\hline \multirow[t]{7}{*}{ Moraceae } & Artocarpus heterophyllus Lam. & & $*$ & & & si \\
\hline & $\begin{array}{l}\text { Brosimum guianense } \\
\text { (Aubl.) Huber }\end{array}$ & & $*$ & & & st \\
\hline & $\begin{array}{l}\text { Cecropia lyratiloba Miquel } \\
\text { var. lyratiloba }\end{array}$ & $*$ & & & & pi \\
\hline & $\begin{array}{l}\text { Clarisia racemosa } \\
\text { Ruiz \& Pavon }\end{array}$ & & & & $*$ & $\mathrm{cl}$ \\
\hline & Ficus insipida Willd. & & $*$ & & & $\mathrm{si}$ \\
\hline & Ficus pulchella Schott & & & & $*$ & $\mathrm{cl}$ \\
\hline & Ficus sp. & & & $*$ & & st \\
\hline \multirow[t]{4}{*}{ Myristicaceae } & Rapanea schwackeana $\mathrm{Mez}$ & $*$ & $*$ & & & pi \\
\hline & $\begin{array}{l}\text { Rapanea umbellata } \\
\text { (Mart.) Mez }\end{array}$ & & $*$ & & & pi \\
\hline & Virola gardneri (A.DC.) Warb. & & & & $*$ & $\mathrm{cl}$ \\
\hline & $\begin{array}{l}\text { Virola oleifera }(\text { Schott }) \\
\text { A.C. Smith }\end{array}$ & & $*$ & & $*$ & st \\
\hline Myrsinaceae & Cybianthus sp. & & $*$ & & & $\mathrm{~s} / \mathrm{d}$ \\
\hline \multirow[t]{13}{*}{ Myrtaceae } & $\begin{array}{l}\text { Calycorectes pohlianus } \\
\text { (Berg) Kiaersk. }\end{array}$ & & & & $*$ & $\mathrm{cl}$ \\
\hline & Calycorectes sellowianus Berg & & & & $*$ & $\mathrm{cl}$ \\
\hline & Calyptranthes lucida Mart. & & & & $*$ & $\mathrm{cl}$ \\
\hline & Calyptranthes sp. & & & & * & s/d \\
\hline & $\begin{array}{l}\text { Campomanesia guaviroba } \\
\text { (DC.) Kiaerst. }\end{array}$ & & & $*$ & & si \\
\hline & Eugenia brasiliensis Lam. & & $*$ & & $*$ & st \\
\hline & $\begin{array}{l}\text { Eugenia compactiflora } \\
\text { (Vell.) Spring }\end{array}$ & & & & $*$ & $\mathrm{cl}$ \\
\hline & Eugenia complanata Gardner & & & & $*$ & $\mathrm{cl}$ \\
\hline & Eugenia glomerata Spring & & & & $*$ & $\mathrm{cl}$ \\
\hline & Eugenia mandioccensis O. Berg & & & & $*$ & $\mathrm{cl}$ \\
\hline & Eugenia phaea Berg & & & & $*$ & $\mathrm{cl}$ \\
\hline & Eugenia prasina Berg & & & & $*$ & st \\
\hline & Eugenia santensis Kiaersk. & & & $*$ & & st \\
\hline
\end{tabular}




\begin{tabular}{|c|c|c|c|c|c|}
\hline família & $\begin{array}{c}5 \\
\text { anos }\end{array}$ & $\begin{array}{c}25 \\
\text { anos }\end{array}$ & $\begin{array}{c}50 \\
\text { anos }\end{array}$ & clímax & $\begin{array}{c}\text { grupo } \\
\text { ecológico }\end{array}$ \\
\hline & Eugenia sp. 1 & & & $*$ & $\mathrm{~s} / \mathrm{d}$ \\
\hline & Eugenia sp. 2 & & & $*$ & $\mathrm{~s} / \mathrm{d}$ \\
\hline & Eugenia sp. 3 & & & * & $\mathrm{s} / \mathrm{d}$ \\
\hline & Eugenia stictosepala Kiaersk. & $*$ & & & st \\
\hline & Eugenia stigmatosa DC. & $*$ & & & st \\
\hline & Eugenia subavenia Berg & & & $*$ & $\mathrm{cl}$ \\
\hline & Gomidesia nitida (Vell.) Kiaersk. & & & * & st \\
\hline & Gomidesia schaueriana Berg & & & $*$ & st \\
\hline & Gomidesia spectabilis (DC.) Berg & & & $*$ & st \\
\hline & Marlierea parviflora Berg & & & $*$ & $\mathrm{cl}$ \\
\hline & $\begin{array}{l}\text { Myrceugenia myrcioides } \\
\text { (Camb.) Legr. \& Kaus. }\end{array}$ & & & $*$ & $\mathrm{cl}$ \\
\hline & Myrcia insularis Gardn. & & & $*$ & $\mathrm{cl}$ \\
\hline & Myrcia rostrata DC. & $*$ & $*$ & & pi \\
\hline & Myrcia sp. & & & $*$ & $\mathrm{~s} / \mathrm{d}$ \\
\hline & $\begin{array}{r}\text { Myrciaria floribunda } \\
\text { (West ex Wild) Berg }\end{array}$ & & & $*$ & $\mathrm{cl}$ \\
\hline & Myrciaria sp. & & & $*$ & $\mathrm{~s} / \mathrm{d}$ \\
\hline & Myrtaceae sp. & & & $*$ & $\mathrm{~s} / \mathrm{d}$ \\
\hline & $\begin{array}{l}\text { Marlierea involucrata } \\
\text { (Berg) Niad }\end{array}$ & & & $*$ & $\mathrm{cl}$ \\
\hline & $\begin{array}{l}\text { Neomitranthes glomerata } \\
\text { (Legr.) Legr. }\end{array}$ & & & * & $\mathrm{cl}$ \\
\hline & Plinia cauliflora (Berg) Sobral & $*$ & & & st \\
\hline & Psidium cattleianum Sabine & $*$ & & * & st \\
\hline \multirow[t]{2}{*}{ Nyctaginaceae } & Guapira opposita (Vell.) Reitz & $*$ & $*$ & & si \\
\hline & Guapira sp. & & & $*$ & $\mathrm{~s} / \mathrm{d}$ \\
\hline Ochnaceae & Ouratea sp. & & $*$ & & $\mathrm{~s} / \mathrm{d}$ \\
\hline \multirow[t]{2}{*}{ Olacaceae } & Heisteria silvianii Schwacke & & & * & $\mathrm{cl}$ \\
\hline & Xylosma glaberrimum Sleum. & & $*$ & & st \\
\hline \multirow[t]{2}{*}{ Palmae } & $\begin{array}{l}\text { Astrocaryum aculeatissimum } \\
\text { (Schott) Burret }\end{array}$ & & * & & st \\
\hline & Euterpe edulis Mart. & & $*$ & $*$ & st \\
\hline Piperaceae & Piper rivinoides Kunth & & * & & si \\
\hline Proteaceae & Roupala sp. & & & * & st \\
\hline Quinaceae & Quina glaziovii Engler & & & * & $\mathrm{cl}$ \\
\hline Rosaceae & Prunus sp. & & & * & $\mathrm{s} / \mathrm{d}$ \\
\hline \multirow[t]{7}{*}{ Rubiacae } & Alibertia sp. & & & * & $\mathrm{cl}$ \\
\hline & $\begin{array}{l}\text { Alibertia elliptica } \\
\text { (Cham.) Schum. }\end{array}$ & & & $*$ & $\mathrm{cl}$ \\
\hline & Alseis floribunda Schott & & $*$ & & st \\
\hline & Amaioua intermedia Mart. & $*$ & & & st \\
\hline & Bathysa sp. & & & $*$ & $\mathrm{~s} / \mathrm{d}$ \\
\hline & Bathysa stipulata (Vell.) Presl. & & & * & st \\
\hline & Coffea arabica Benth. & & $*$ & & si \\
\hline
\end{tabular}




\begin{tabular}{|c|c|c|c|c|c|c|}
\hline família & espécie & $\begin{array}{c}5 \\
\text { anos }\end{array}$ & $\begin{array}{c}25 \\
\text { anos }\end{array}$ & $\begin{array}{c}50 \\
\text { anos }\end{array}$ & clímax & $\begin{array}{c}\text { grupo } \\
\text { ecológico }\end{array}$ \\
\hline & $\begin{array}{l}\text { Coussarea meridionali } \\
\text { (Vell.) Muell. Arg. var. } \\
\text { porophylla (Vell.) M. Gomes }\end{array}$ & & & & $*$ & $\mathrm{cl}$ \\
\hline & Coussarea sp. & & & & $*$ & $\mathrm{~s} / \mathrm{d}$ \\
\hline & $\begin{array}{l}\text { Faramea multiflora A. C. Rich } \\
\text { ex DC. var. salicifolia } \\
\text { (Presl.) Steyerm. }\end{array}$ & & & & $*$ & $\mathrm{cl}$ \\
\hline & $\begin{array}{l}\text { Faramea pachyantha } \\
\text { Muell. Arg. var. mandiocana } \\
\text { (Muell. Arg.) Muell. Arg. }\end{array}$ & & & & $*$ & $\mathrm{cl}$ \\
\hline & Faramea sp. & & $*$ & & & $\mathrm{~s} / \mathrm{d}$ \\
\hline & Ixora aff. gardneriana Benth. & & & & $*$ & $\mathrm{cl}$ \\
\hline & $\begin{array}{l}\text { Ixora aff. membranacea } \\
\text { Muell. Arg. }\end{array}$ & & & & $*$ & $\mathrm{cl}$ \\
\hline & Posoqueria acutifolia Mart. & & & & $*$ & $\mathrm{cl}$ \\
\hline & $\begin{array}{l}\text { Psychotria brasiliensis (Vell.) } \\
\text { Muel. Arg. }\end{array}$ & & & $*$ & & st \\
\hline & Psychotria carthaginensis Jacq. & & $*$ & $*$ & & st \\
\hline & Psychotria nuda Wawra & & & & $*$ & st \\
\hline & Psychotria sp. & & & $*$ & $*$ & $\mathrm{~s} / \mathrm{d}$ \\
\hline & Psychotria vellosiana Benth. & & $*$ & $*$ & & $\mathrm{cl}$ \\
\hline & Rubiaceae sp. & & & $*$ & & $\mathrm{~s} / \mathrm{d}$ \\
\hline & Rudgea langsdorfii Muell. Arg. & & $*$ & & & st \\
\hline & Rudgea sp. & & & $*$ & & st \\
\hline & $\begin{array}{l}\text { Rustia formosa } \\
\text { (Cham. \& Schlecht.) Kl. }\end{array}$ & & & & * & $\mathrm{cl}$ \\
\hline & Rustia gracilis K. Schum & & & & $*$ & $\mathrm{cl}$ \\
\hline & Rustia sp. & & & & $*$ & $\mathrm{~s} / \mathrm{d}$ \\
\hline & $\begin{array}{l}\text { Simira sampaioana } \\
\quad \text { (Standl.) Steyermark }\end{array}$ & & $*$ & & & st \\
\hline \multirow[t]{2}{*}{ Rutaceae } & Citrus sp. & & & $*$ & & pi \\
\hline & Dictyoloma incanescens DC. & & $*$ & $*$ & & st \\
\hline \multirow[t]{5}{*}{ Sapindaceae } & $\begin{array}{l}\text { Allophylus heterophyllus } \\
\text { (Camb.) Radlk. }\end{array}$ & & & & $*$ & $\mathrm{cl}$ \\
\hline & Allophylus petiolulatus Radlk. & & $*$ & $*$ & & si \\
\hline & Cupania oblongifolia Cambess. & & $*$ & & $*$ & si \\
\hline & Matayba guianensis Aubl. & & $*$ & & & st \\
\hline & $\begin{array}{l}\text { Tripterodendron filicifolium } \\
\text { Radlk. }\end{array}$ & & & & $*$ & $\mathrm{cl}$ \\
\hline \multirow[t]{5}{*}{ Sapotaceae } & Ecclinusa ramiflora Mart. & & & & $*$ & st \\
\hline & $\begin{array}{l}\text { Micropholis cuneata } \\
\text { (Raumkier) Pierre }\end{array}$ & & & & $*$ & st \\
\hline & $\begin{array}{l}\text { Chrysophyllum flexuosum } \\
\text { Mart. }\end{array}$ & & $*$ & & $*$ & st \\
\hline & Pouteria sp. & & & & $*$ & $\mathrm{~s} / \mathrm{d}$ \\
\hline & Pradosia kulmannii Toledo & & & & $*$ & $\mathrm{cl}$ \\
\hline
\end{tabular}




\begin{tabular}{|c|c|c|c|c|c|c|}
\hline família & espécie & $\begin{array}{c}5 \\
\text { anos }\end{array}$ & $\begin{array}{c}25 \\
\text { anos }\end{array}$ & $\begin{array}{c}\mathbf{5 0} \\
\text { anos }\end{array}$ & clímax & $\underset{\text { ecológico }}{\text { grupo }}$ \\
\hline & $\begin{array}{l}\text { Pradosia lactescens } \\
\text { (Vell.) Radlk. }\end{array}$ & & & & * & $\mathrm{cl}$ \\
\hline & Sapotaceae sp. & & & & * & $\mathrm{s} / \mathrm{d}$ \\
\hline \multirow[t]{3}{*}{ Solanaceae } & $\begin{array}{l}\text { Capsicum cf. schottianum } \\
\text { Sendt. }\end{array}$ & $*$ & & & & pi \\
\hline & Solanum argenteum Dun. & * & & & & pi \\
\hline & Solanum carautae Carvalho & * & $*$ & & & pi \\
\hline Tiliaceae & Luehea divaricata Mart. & & & & * & st \\
\hline Thymaeliaceae & Daphnopsis sp. & & & & $*$ & $\mathrm{cl}$ \\
\hline Ulmaceae & Trema micrantha (L.) Blume & * & & & & pi \\
\hline Verbenaceae & Aegiphila sellowiana Cham. & $*$ & & & * & pi \\
\hline Violaceae & $\begin{array}{l}\text { Amphirrhox longifolia } \\
\text { (St. Hil.) Spreng. }\end{array}$ & & & * & * & st \\
\hline \multirow[t]{3}{*}{ Vochysiaceae } & $\begin{array}{l}\text { Qualea cryptantha } \\
\text { Spreng. ex Warm. }\end{array}$ & & & $*$ & * & $\mathrm{cl}$ \\
\hline & Qualea glaziovii Warm. & & & & * & $\mathrm{cl}$ \\
\hline & Vochysia bifalcata Warm. & & & & * & $\mathrm{cl}$ \\
\hline
\end{tabular}

Os resultados da classificação sucessional das espécies encontram-se na figura 2 . $\mathrm{O}$ grupo ecológico que alcançou maior valor percentual (65\% das espécies) foi o das pioneiras na área de 5 anos. Em ordem decrescente, encontramse as climáxicas na área climáxica (49\%), as secundárias tardias na área de 50 anos (47\%) e este mesmo grupo na área de 25 anos (44\%). O grupo das pioneiras sofreu uma redução acentuada entre a área de 5 e 25 anos, quando passou de $65 \%$ para $11 \%$. Daí para frente, este grupo foi decaindo de forma menos intensa, alcançando $11 \%, 9 \%$ e $0,7 \%$, respectivamente, nas áreas de 25 anos, 50 anos e climáxica. As secundárias iniciais apresentaram valores relativamente próximos nas três primeiras áreas $(30 \%, 28 \%$ e $23 \%)$, respectivamente, reduzindo para $4 \%$ na área climáxica. $\mathrm{O}$ grupo das secundárias tardias exibiu um acréscimo acentuado da área de 5 anos para a de 25 anos (de $3 \%$ para 44\%), mantendo este patamar na área de 50 anos (47\%) e decaindo na área climáxica para $28 \%$.

A distribuição percentual das espécies pelos grupos ecológicos permitiu a separação em
3 situações: a) com dominância de pioneiras (a área de 5 anos); b) com dominância das secundárias iniciais e tardias (as áreas de $25 \mathrm{e}$ 50 anos) e c) com dominância das espécies climáxicas (a área climáxica). Uma questão que se coloca na bibliografia (Leitão Filho et al., 1993) é o retorno funcional e estrutural da floresta secundária à floresta climáxica. Pela ótica dos grupos ecológicos aqui observados, este retorno parece ser muito lento, de vez que o incremento de espécies climáxicas da área de 25 para a de 50 anos é muito baixo (de $4,2 \%$ para $6,3 \%$, respectivamente), o que sugere que estas duas áreas permanecerão com a presente composição de grupos ecológicos por muito tempo. Comprova ainda esta hipótese o comportamento de ligeira redução das secundárias iniciais das áreas de 25 e 50 anos (de $28,6 \%$ para $23,8 \%$ ), assim como o inexpressivo acréscimo das secundárias tardias nas mesmas áreas, que passaram de 44,3\% para 47,6\%. Por outro lado, a presença de algumas poucas espécies pioneiras e secundárias iniciais na floresta climáxica pode indicar: a) uma herança 


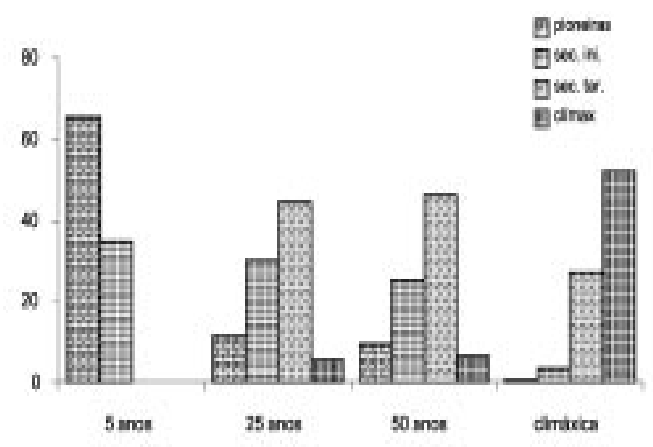

Figura 2 - Distribuição percentual das espécies nos grupos ecológicos das quatro áreas de estudos.

de antigas clareiras naturais; b) um verdadeiro "estoque de emergência", a ser disponibilizado no caso de abertura de clareiras. Reforça a idéia de clímax para a área do Pico do Papagaio a presença de Quararibea turbinata, Crysophyllum flexuosum, Euterpe edulis, Virola oleifera, Ficus pulchella e Brosimum glaziovii, referidas na literatura como características de situação climáxica (Leitão Filho et al., 1993; Kurtz \& Araújo, 2000). Quanto às Ocotea, Lima \& Guedes-Bruni (1997) afirmam que o gênero (presente no Pico do Papagaio com 6 espécies) é característico de florestas bem preservadas.

Aspectos da estrutura: A Tabela 4 apresenta as características gerais da vegetação no gradiente estudado. Considerando-se como rara a espécie que foi amostrada com um único indivíduo, tem-se nas áreas climáxica, de 50 e de 25 anos, um total respectivo de 44,4\%, 41,2\% e $32,8 \%$, de espécies com esta característica, enquanto na área de 5 anos apenas 3,8\% (ou seja, uma única espécie) foi assim classificada. A distribuição percentual do número de espécies raras guardou uma relação maior com a idade sucessional do que com o número total de espécies. Ou seja: o aumento do número de espécies raras seguiu a forma de um gradiente nas 4 áreas estudadas. $\mathrm{O}$ valor encontrado para a área climáxica $(44,4 \%)$ é alto, mas não é distante dos encontrados por outros autores que estudaram regiões assemelhadas, como 48,7\% obtido por Mantovani et al. (1990) em Salesópolis (SP), ou 45,2\% por Oliveira et al. (1995) na vertente Sul do Maciço da Tijuca (RJ), 40,4\% por Melo et al. (1998) na Juréia (SP) e 38,2\% encontrado por Silva (1980) em Ubatatuba (SP).

Já para a densidade total por área (número de indivíduos por unidade de área), não foi verificado o padrão de gradiente, observado para a maioria dos demais descritores da vegetação, uma vez que a maior densidade $(2.784$ ind./ha) ocorreu na área de 25 anos, seguida da área de 50 anos (2.273 ind./ha), da área climáxica (1.996 ind./ha) e da de 5 anos (1.915 ind./ha). De uma maneira geral, tratam-se de valores intermediários de densidade, de vez que em outras áreas conservadas foram obtidos valores mais baixos como 1.369 ind./ha em Guapimirim (Kurtz \& Araújo, 2000)e mais altos - 2.091 ind./ha (Guedes-Bruni et al., 1997) em Macaé de Cima, ambos no Rio de Janeiro. Nesta mesma localidade, Pessoa et al. (1977), estudando uma floresta secundária de 30 anos, encontrou também um valor mais alto de densidade (2.217 ind./ha) em relação à mata conservada próxima, estudada por Guedes-Bruni et al. (loc. cit.). Este fato está de acordo com a maior densidade observada na nossa área de 25 anos. O número de indivíduos por espécie decresceu na medida do avanço do tempo sucessional, variando entre 19,1 e 3,8 ind./ espécie, respectivamente, nas áreas de 5 anos e climáxica.

A medida de dominância empregada no presente trabalho (área basal) apresentou valores crescentes: $5,6 \mathrm{~m}^{2} / \mathrm{ha}, 26,3 \mathrm{~m}^{2} / \mathrm{ha}, 32,4$ $\mathrm{m}^{2} /$ ha e $57,9 \mathrm{~m}^{2} / \mathrm{ha}$, respectivamente nas áreas de 5 anos, 25 anos, 50 anos e climáxica, o que está de acordo com a caracterização sucessional proposta por Budowski (1966). A razão de incremento da área basal de um estágio para outro foi de 4,7 vezes da área de 5 para a de 25 anos, de 1,2 vezes entre as áreas de 25 e 50 anos e de 1,8 vezes desta última para a área climáxica. $\mathrm{Ou}$ seja, nos primeiros 25 anos verificou-se o maior incremento de área basal de todo o gradiente sucessional estudado, o que está de acor- 
Tabela 4 - Principais características vegetacionais do gradiente sucessional estudado na Ilha Grande, RJ

\begin{tabular}{lllll}
\hline Característica & $\mathbf{5}$ anos & $\mathbf{2 5}$ anos & $\mathbf{5 0}$ anos & climáxica \\
\hline número de espécies & 26 & 70 & 63 & 134 \\
espécies raras & $1(3,8 \%)$ & $23(32,8 \%)$ & $27(41,3 \%)$ & $57(42,5 \%)$ \\
densidade (ind./ha) & 1.915 & 2.784 & 2.273 & 1.996 \\
n. de indivíduos/espécie & 19,1 & 10,3 & 9,38 & 3,8 \\
área basal (m²/ha) & 5,6 & 26,3 & 32,4 & 57,9 \\
coef. de var. dos diâmetros dos caules & $51,0 \%$ & $84,2 \%$ & $93,3 \%$ & $121,0 \%$ \\
indivíduos amostrados & 498 & 724 & 591 & 519 \\
área amostrada (m $\left.{ }^{2}\right)$ & 2.600 & 2.600 & 2.600 & 2.600 \\
diâmetro máximo & $16 \mathrm{~cm}$ & $53 \mathrm{~cm}$ & $52 \mathrm{~cm}$ & $117 \mathrm{~cm}$ \\
diâmetro médio & $4,7 \mathrm{~cm}$ & $7,5 \mathrm{~cm}$ & $9,6 \mathrm{~cm}$ & $12,2 \mathrm{~cm}$ \\
altura máxima & $12 \mathrm{~m}$ & $27 \mathrm{~m}$ & $30 \mathrm{~m}$ & $45 \mathrm{~m}$ \\
altura média & $3,7 \mathrm{~m}$ & $7,0 \mathrm{~m}$ & $8,8 \mathrm{~m}$ & $11 \mathrm{~m}$ \\
coef. de var. das alt. dos indivíduos & 42,0 & 60,7 & 78,6 & 89,0 \\
troncos múltiplos & $18,3 \%$ & $8,8 \%$ & $7,6 \%$ & $0,9 \%$ \\
indivíduos mortos em pé & $15,1 \%$ & $7,8 \%$ & $6,3 \%$ & $1,5 \%$ \\
índice de Shannon (nats/ind.) & 2,51 & 3,33 & 3,10 & 4,28 \\
índice de equabilidade de Pielou & 0,77 & 0,78 & 0,75 & 0,87 \\
\hline
\end{tabular}

do com algumas teorias de sucessão ecológica (Odum, 1969; Horn, 1974).Curiosamente, Pessoa et al. (1997), utilizando os mesmos critérios de inclusão que os nossos, encontrou numa floresta de 30 anos em Macaé de Cima (RJ) um valor de área basal muito próximo do encontrado na nossa de 25 anos $\left(27,9 \mathrm{~m}^{2} /\right.$ ha contra $26,3 \mathrm{~m}^{2} / \mathrm{ha}$, respectivamente). A área basal do Pico do $\mathrm{Pa}$ pagaio também se aproxima dos $62,8 \mathrm{~m}^{2} / \mathrm{ha}$ encontrados por Zaú (1994) no Morro do Sumaré (RJ) e dos $57,28 \mathrm{~m}^{2} /$ ha encontrados por Kurtz \& Araújo (2000) em Guapimirim. Usando-se este parâmetro como um indicador da recuperação estrutural da floresta, temos, portanto, que a área de 50 anos apresentou $56 \%$ da área basal da climáxica. Este valor é também muito próximo dos $60 \%$ encontrados por Saldarriaga \& Uhl (1991) na Amazônia peruana, quando compararam florestas de 70 anos com estágios maduros.

A distribuição dos coeficientes de variação dos diâmetros dos troncos apresentou um padrão crescente em relação às idades sucessionais: para as áreas de 5 anos, 25 anos, 50 anos e climáxica, os valores obtidos foram, respectivamente: $51,0 \%, 84,2 \%, 93,3 \%$ e $121,0 \%$. O mesmo resultado foi observado para as alturas, onde, na mesma seqüência, os coeficientes de variação foram: $42,0 \% ; 60,7 \%$; $78,6 \% ; 89,0 \%$. Este padrão espelha uma crescente diversidade de gerações e formas de vida, e uma crescente complexidade estrutural que ocorre ao longo do tempo e está de acordo com a classificação estrutural e funcional de florestas secundárias proposta por Clark (1996).

Como seria de se esperar em relação às características individuais das espécies, os maiores diâmetros e alturas (tanto médios como absolutos) foram encontrados na área climáxica. Nesta, dois portentosos indivíduos de Vochysia bifalcata e Pradosia kulmanii atingiram, respectivamente, 45 e $42 \mathrm{~m}$ de altura, ostentando troncos com diâmetros de 86 e $108 \mathrm{~cm}$, respectivamente. Como seria de se esperar, os diâmetros e alturas médios das áreas de 5 anos, 25 anos, 50 anos e climáxica foram crescentes (conforme mostrou a Tab. 4).

A ocorrência de troncos múltiplos - aqui considerados como aqueles que apresentam 
ramificações superiores a 2,5cm a mais de $1,3 \mathrm{~m}$ do solo - diminuiu em relação à idade sucessional. Nas áreas de 5 anos, 25 anos, 25 anos, 50 anos e climáxica, a porcentagem de troncos ramificados foi respectivamente $18,3 \%, 8,8 \%$, $7,6 \%$ e $0,9 \%$. Este padrão de gradiente era esperado, pois estes são produzidos pela rebrota de tocos quando da implantação da roça caiçara. Após a derrubada e incendimento da vegetação, os caiçaras mantém os tocos no lugar, que se mantêm vivos rebrotando ao longo do cultivo e principalmente quando do abandono da área para pousio. Assim, a taxa decrescente de troncos múltiplos observada pode ser considerada como uma herança da roça que precedeu as florestas secundárias estudadas. Com a substituição das populações pioneiras que sofreram o corte, esta taxa vai decaindo até chegar perto de zero na área não alterada. A taxa de mortalidade de árvores adultas medida por meio de contagem de troncos mortos ainda de pé em relação aos troncos vivos apresentou valores de $15,1 \%, 7,8 \%, 6,3 \%$ e $1,5 \%$, respectivamente nas áreas de 5 anos, 25 anos, 50 anos e climáxica. Pessoa et al. (1997) encontraram uma porcentagem de árvores mortas em floresta de 30 anos em Macaé de Cima de 10,5\%, valor próximo ao encontrado na nossa área de 25 anos $(7,8 \%)$. Bastante similar foi o valor reportado por Kurtz \& Araújo (2000) em área climáxica em Guapimirim, de 1,3\% de árvores mortas em pé. $\mathrm{Na}$ Reserva Biológica do Tinguá (RJ), Rodrigues (1996) encontrou um total de 2,3\% de árvores mortas. O padrão de árvores mortas em pé segue a forma de um gradiente nas 4 áreas estudadas, inversamente proporcional à idade. Segundo Budowski (1966), a expectativa de vida das espécies dominantes no estágio pioneiro é de 1 a 3 anos, aumentando para 10 a 25 no estágio secundário inicial, para 40 a 100 anos no estágio secundário tardio, podendo atingir de 100 a 1.000 ou mais anos no clímax, o que pode explicar os números aqui encontrados. A figura 3 apresenta as porcentagens relativas aos troncos mortos em pé e os troncos ramificados.

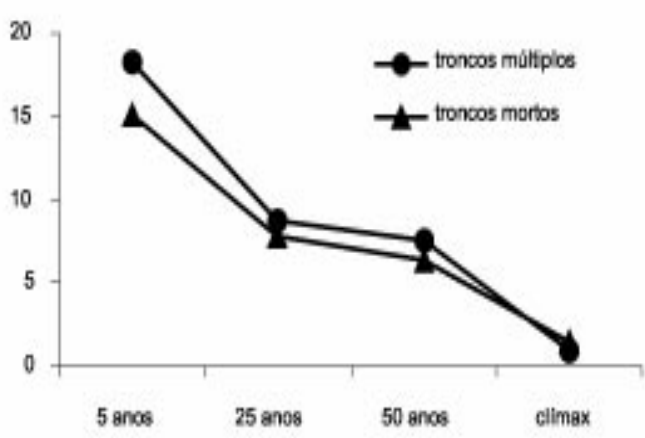

Figura 3 - Porcentagem de troncos mortos e ramificados nas áreas de 5 anos, 25 anos, 50 anos e climáxica.

A diversidade de uma comunidade pode ser medida pelo número de espécies presentes ou por meio de índices, como o de Shannon. Segundo Martins (1991), este índice fornece uma boa indicação da diversidade de espécies e pode ser utilizado para comparar florestas de diferentes locais, como é o caso deste estudo. Ainda segundo este autor, os valores de diversidade para a floresta atlântica variam de 3,61 a 4,07 nats/ind. O gradiente estudado na Ilha Grande apresentou os valores de 2,51; 3,33; 3,10 e 4,28 nats/ind., respectivamente nas áreas de 5 anos, 25 anos, 50 anos e climáxica. De uma maneira geral, os índices de diversidade foram semelhantes aos de outros estudos feitos em áreas sucessionais de idade comparável. Em relação ao estágio pioneiro (5 anos), cujo H' na Ilha Grande foi de 2,51 nats/ ind., em Iporanga (SP), uma capoeira de mesma idade apresentou um índice idêntico (Torezan, 1995). Em Macaé de Cima (RJ), em área de 30 anos (Pessoa et al., 1997), encontraram $\mathrm{H}^{\prime}=3,66$ nats/ind., enquanto na área de 25 anos da Ilha Grande, $H^{\prime}=3,33$ nats/ind. Atribui-se esta semelhança à origem comum de todas as áreas - roças de subsistência. Segundo Connel (1978), é esperado que a diversidade de espécies seja maior em estágios préclimáxicos da sucessão. A ser verdadeira esta afirmação, este fato só poderia ser encontrado no presente estudo na área de 25 anos, cujo número de espécies suplanta a de 50 anos. 
Em ecossistemas maduros e assemelhados à floresta climáxica do Pico do Papagaio, os resultados apresentados pela bibliografia encontram-se na Tabela 5.

Das áreas comparadas, o valor de H' encontrado para a área clímax da Ilha Grande é relativamente elevado. Segundo Kurtz \& Araújo (2000), vários fatores podem interferir nos índices de diversidade obtidos, seja o método de amostragem ou o critério de inclusão dos indivíduos. A diversidade é um reflexo de dois componentes: a riqueza de espécies e a equabilidade (relacionada à contribuição numérica de cada espécie). Assim, diferenças metodológicas podem alterar estes resultados. No caso da Ilha Grande, a diversidade pode ser considerada muito alta, pois o estabelecimento de parcelas contíguas provavelmente minimizou a incorporação da diversidade beta, rela- cionada, por exemplo, a gradientes altitudinais (Mantovani, 1999). Por outro lado, o nosso critério de inclusão e de outros estudos acima listados (dap $>2,5 \mathrm{~cm}$ ) favorece a amostragem de elementos do sub-bosque, constituída geralmente de espécies com populações numerosas.

Com relação ao índice de equabilidade de Pielou, os valores encontrados foram 0,$77 ; 0,78$; 0,75 e 0,87 , respectivamente nas áreas de 5 anos, 25 anos, 50 anos e climáxica. Os menores valores de equabilidade obtidos nas áreas de 5 anos, 25 anos, 50 anos indicam que nestas áreas algumas espécies apresentaram maior número de indivíduos do que na área clímax. Isto deve ser reflexo de que, nestas áreas, algumas são dominantes como se verá a seguir -, enquanto na área climáxica as populações apresentam quantidades de indivíduos mais proporcionais entre si, apesar do alto número de espécies raras e exclusivas.

Tabela 5 - Parâmetros fitossociológicos e de diversidade encontrados em floresta atlântica costeira climáxica no sudeste do Brasil. (dap = diâmetro à 1,3m do solo (critério de inclusão); n.d. = não disponível; H' = índice de diversidade de Shannon (nats/ind.) e $\mathrm{S}$ = índice de similaridade de Sorensen, em relação à área climáxica do Pico do Papagaio da Ilha Grande)

\begin{tabular}{|c|c|c|c|c|c|c|c|}
\hline Local & Método & $\underset{(\mathbf{c m})}{\text { dap }}$ & $\begin{array}{l}\text { Área } \\
\text { basal } \\
\left(\mathbf{m}^{2} / \mathbf{h a}\right)\end{array}$ & $\begin{array}{l}\text { Número } \\
\text { espécies }\end{array}$ & $\mathbf{H}^{\prime}$ & $\mathbf{S}$ & Autor \\
\hline Cubatão, SP & $\begin{array}{c}\text { parcelas } \\
(0,4 \mathrm{ha})\end{array}$ & 6,3 & n.d. & 145 & 3,77 & 16,2 & Leitão F., 1993 \\
\hline Ubatuba, SP & $\begin{array}{l}\text { pontos } \\
(160)\end{array}$ & 10,0 & n.d. & 123 & 3,49 & 15,26 & Silva, 1980 \\
\hline Juréia, SP & $\begin{array}{l}\text { pontos } \\
(200)\end{array}$ & 9,5 & n.d. & 155 & 4,19 & n.d. & Mantovani, 1993 \\
\hline Salesópolis, SP & $\begin{array}{l}\text { pontos } \\
(100)\end{array}$ & 15,0 & 39 & 104 & 3,31 & n.d. & Mantovani et al. 1990 \\
\hline $\begin{array}{l}\text { Ilha do Cardoso, } \\
\text { SP }\end{array}$ & $\begin{array}{l}\text { parcelas } \\
\text { (1ha) }\end{array}$ & 2,5 & 47,9 & 157 & 3,64 & 18,0 & Melo et al., 1998 \\
\hline Tinguá, RJ & $\begin{array}{l}\text { pontos } \\
(200)\end{array}$ & 2,5 & n.d. & 189 & 4,36 & 15,4 & Rodrigues, 1996 \\
\hline Guapimirim, RJ & $\begin{array}{l}\text { pontos } \\
(150)\end{array}$ & 5,0 & 57,28 & 138 & 4,2 & 23,5 & Kurtz \& Araújo, 2000 \\
\hline Ubatuba, RJ & $\begin{array}{c}\text { parcelas } \\
(0,4 \mathrm{ha})\end{array}$ & 6,7 & n.d. & 120 & 4,07 & n.d. & Sanchez et al., 1999 \\
\hline $\begin{array}{l}\text { Maciço da Tijuca, } \\
\text { RJ (vertente Sul) }\end{array}$ & $\begin{array}{r}\text { parcelas } \\
(0,25 \mathrm{ha})\end{array}$ & 2,5 & n.d. & 139 & 4,2 & 27,4 & Oliveira et al., 1995 \\
\hline $\begin{array}{l}\text { Ilha Grande, RJ } \\
\text { (área clímax) }\end{array}$ & $\begin{array}{r}\text { parcelas } \\
(0,26 \mathrm{ha})\end{array}$ & 2,5 & 57,95 & 134 & 4,31 & - & este estudo \\
\hline
\end{tabular}

Rodriguésia 53 (82): 33-58. 2002 
Nas Tabelas 6 e seguintes, são apresentadas variáveis fitossociológicas das 10 espécies com maior valor de importância. Na área de 5 anos (Tabela 6), o valor de importância (VI) tem mais de um terço de seu total composto apenas por duas espécies (Aegiphila sellowiana e Anadenanthera colubrina) que alcançaram, respectivamente, $54,4 \%$ e 50,8\%. Estes valores foram elevados em função de ambas terem alcançado porcentagens igualmente altas de densidade, frequiência e dominância. $\mathrm{O}$ alto valor de importância (VI) alcançado pelo cobi (como é chamado no local o angico - Anadenanthera colubrina) tem uma explicação de caráter etnobotânico. Sua casca é utilizada pelos caiçaras para o tingimento de redes, o que justifica o interesse dos mesmos em tê-lo próximo às residências. Há ainda relato de moradores levarem sementes desta espécie para outros locais onde esta não ocorre (Oliveira \& Coelho Netto, 2001). Por outro lado, a alta dominância $(26,98 \%)$ e densidade relativas $(13,1 \%)$ obtidas pela espécie pode ser responsável pela restauração da fertilidade do solo das roças caiçaras em tempo relativamente muito curto, em função da nodulação por bactérias diazotróicas (Norma Rumjanek, comunicação pessoal). As espécies de maior densidade e freqüência foram Aegiphila sellowiana, Anadenanthera colubrina e Cecropia lyratiloba var. lyratiloba. Quanto a esta última, apesar de ter atingido alto VI, apresentou baixa dominância $(0,39 \%)$. Ordenando-se as 10 espécies com maior VI, temos: Aegiphila sellowiana, Anadenanthera colubrina, Cecropia lyratiloba var. lyratiloba, Rapanea schwackeana, Vernonia polyanthes, Trema micrantha, Tibouchina estrellensis, Cybistax antisyphilitica, Miconia cinnamomifolia e Solanum argenteum que, juntas, perfazem $80,3 \%$ do seu valor total, ou seja, estas espécies apresentaram elevada contribuição individual para o VI de toda a comunidade. Estas mesmas espécies contribuem com $84,7 \%$ da densidade de todas as espécies, com 75,4\% da frequiência de todas e com $81,2 \%$ da dominância de toda a comunidade. Esta concentração de muitos atributos fitossociológicos em poucas espécies é uma característica de estágios iniciais da sucessão ecológica (Delamonica, 1997; Kurtz \& Araújo, 2000).

$\mathrm{Na}$ área de 25 anos (Tabela 7), as 10 espécies com valores mais altos de VI (Miconia cinnamomifolia, Miconia prasina, Cordia magnoliaefolia, Brosimum guianense, Psychotria carthaginensis, Anadenanthera colubrina, Cabralea canjerana, Casearia decandra, Amaioua intermedia e Ocotea glaziovii) perfizeram $63,2 \%$ do mesmo, o que mostra certa redução em relação ao resultado

Tabela 6 - Ordenação das 10 espécies da área de 5 anos com maior valor de importância (Vila do Aventureiro, RBEPS) (n $=\mathrm{n}$. de indivíduos; $\mathrm{DR}=$ densidade relativa; $\mathrm{FR}=$ frequiência relativa; $\mathrm{DoR}=$ dominância relativa e VI $=$ valor de importância)

\begin{tabular}{lccccc}
\hline nome & n & DR & FR & DoR & VI \\
\hline Aegiphila sellowiana Cham. & 90 & 18,1 & 13,3 & 22,98 & 54,4 \\
Anadenanthera colubrina (Vell.) Bren. & 65 & 13,1 & 10,8 & 26,98 & 50,8 \\
Cecropia lyratiloba Miquel var. lyratiloba & 82 & 16,5 & 12,3 & 0,39 & 29,2 \\
Rapanea schwackeana Mez. & 62 & 12,4 & 11,3 & 0,19 & 23,9 \\
Vernonia polyanthes Less. & 11 & 2,2 & 3,1 & 18,16 & 23,4 \\
Trema micrantha (L.) Blume & 46 & 9,2 & 7,7 & 0,80 & 17,7 \\
Tibouchina estrellensis Cogn. & 38 & 7,6 & 6,7 & 0,04 & 14,3 \\
Cybistax antisyphilitica (Mart.) Mart. ex DC. & 20 & 4,0 & 6,2 & 1,03 & 11,2 \\
Miconia cinnamomifolia (DC.) Naud. & 4 & 0,8 & 2,1 & 5,44 & 8,3 \\
Solanum argenteum Dun. & 4 & 0,8 & 2,1 & 5,22 & 8,1 \\
\hline
\end{tabular}


Tabela 7 - Ordenação das 10 espécies da área de 25 anos com maior valor de importância (n = n. de indivíduos; DR = densidade relativa; $\mathrm{FR}$ = freqüência relativa; $\mathrm{DoR}=$ dominância relativa e VI = valor de importância)

\begin{tabular}{llllll}
\hline nome & n & Dr & FR & DoR & VI \\
\hline Miconia cinnamomifolia (DC.) Naud. & 45 & 6,2 & 4,6 & 25,9 & 36,74 \\
Miconia prasina (SW.) DC. & 76 & 10,5 & 5,5 & 4,3 & 20,35 \\
Cordia magnoliaefolia Cham. & 69 & 9,5 & 6,1 & 4,1 & 19,80 \\
Brosimum guianense (Aubl.) Huber & 59 & 8,1 & 5,2 & 6,2 & 19,59 \\
Psychotria carthaginensis Jacq. & 64 & 8,8 & 5,5 & 4,1 & 18,43 \\
Anadenanthera colubrina (Vell.) Bren. & 18 & 2,5 & 4,0 & 11,7 & 18,22 \\
Cabralea canjerana (Vell.) Mart. & 29 & 4,0 & 4,3 & 8,9 & 17,18 \\
Casearia decandra Jacq. & 47 & 6,5 & 4,9 & 4,0 & 15,40 \\
Amaioua intermedia Mart. & 46 & 6,4 & 3,7 & 3,7 & 13,72 \\
Ocotea glaziovii Mez & 30 & 4,1 & 4,0 & 2,2 & 10,37 \\
\hline
\end{tabular}

obtido na área de 5 anos. Dentro destas mesmas 10 espécies, apenas o cobi (Anadenanthera colubrina) pertence a este grupo na área de 5 anos. Naquela área, esta espécie apresentou valores muito mais elevados de densidade, freqüência e dominância. Apesar disso, a espécie apresentou o segundo maior valor de dominância de toda a área $(11,7 \%)$. No entanto, tratam-se apenas de exemplares adultos e, como foi observado em campo, a maioria encontra-se atacada por cupins, aparentando tratar-se de população em declínio. Esta suposição é também baseada pela não-ocorrência desta espécie na área seguinte, a de 50 anos. Na área de 25 anos, a espécie de maior VI, Miconia cinnamomifolia, representou $36,7 \%$ do mesmo, enquanto na área de 5 anos esta espécie estava presente com dominância muito mais baixa do que a observada na presente área $(5,4 \%$ contra $25,9 \%$, respectivamente). Com relação à dominância, os maiores destaques foram Miconia cinnamomifolia $(25,9 \%)$ e Anadenanthera colubrina $(11,7 \%)$.

A Tabela 8 mostra os parâmetros fitossociológicos relativos à área de 50 anos. Neste estágio, as 10 espécies com valores mais altos de VI foram Lamanonia ternata, Hieronyma alchorneoides, Miconia cinnamomifolia, Allophylus petiolulatus, Piper rivinoides,
Nectandra membranacea, Myrcia rostrata, Mollinedia acutissima, Inga marginata e Cyathea delgadii, que, juntas, totalizaram um valor um pouco mais elevado que o anterior, 69,3\% do mesmo. Estas mesmas 10 espécies contribuíram com $72,1 \%$ da densidade de todas as espécies, com $53,3 \%$ da frequiência de todas e com $82,5 \%$ da dominância de toda a comunidade. Com relação ao grupo das 10 espécies com maior VI do estágio anterior, apenas o jacatirão (Miconia cinnamomifolia) permaneceu neste mesmo grupo no presente estágio. Aqui esta espécie apresentou como destaque a elevada dominância relativa $(27,7 \%)$. No entanto, neste estágio sucessional, esta espécie apresentou distribuição de alturas e diâmetros similares à observada no cobi (Anadenanthera colubrina) no estágio anterior, ou seja, é composta exclusivamente por exemplares adultos, não se verificando mais o recrutamento de indivíduos jovens. Pereira (1999) detectou que a mortalidade de plântulas foi absoluta em área de sucessão mais avançada na Reserva Biológica de Poço das Antas, o que evidencia a dependência da espécie em relação ao fator luminosidade, no que diz respeito ao seu estabelecimento e sobrevivência.

Em termos de densidade, as espécies de maior destaque foram Lamanonia ternata 
(16,6\%), Hieronyma alchorneoides (12,0\%) e Allophylus petiolulatus (12,0\%). Estas duas primeiras espécies também foram as que obti- veram maior dominância, juntamente com Miconia cinnamomifolia (respectivamente $17,4 \%, 18,6 \%$ e $27,7 \%)$.

Tabela 8 - Ordenação das 10 espécies da área de 50 anos com maior valor de importância $(\mathrm{n}=\mathrm{n}$. de indivíduos; DR = densidade relativa; $F R=$ frequiência relativa; $\mathrm{DoR}=$ dominância relativa e VI = valor de importância)

\begin{tabular}{|c|c|c|c|c|c|}
\hline nome & $\mathbf{n}$ & Dr & $\mathbf{F R}$ & DoR & VI \\
\hline Lamanonia ternata Vell. & 98 & 16,6 & 7,2 & 17,40 & 41,2 \\
\hline Hieronyma alchorneoides Fr. Al. & 71 & 12,0 & 8,2 & 18,64 & 38,9 \\
\hline Miconia cinnamomifolia (DC.) Naud. & 24 & 4,1 & 4,1 & 27,70 & 35,9 \\
\hline Allophylus petiolulatus Radlk. & 71 & 12,0 & 6,5 & 3,00 & 21,5 \\
\hline Piper rivinoides Kunth & 56 & 9,5 & 6,9 & 0,90 & 17,2 \\
\hline Nectandra membranacea (Sw.) Griseb. & 25 & 4,2 & 5,5 & 6,57 & 16,3 \\
\hline Myrcia rostrata DC. & 29 & 4,9 & 4,5 & 6,40 & 15,8 \\
\hline Mollinedia acutissima Perk. & 22 & 3,7 & 4,1 & 0,39 & 8,2 \\
\hline Inga marginata Willd. & 19 & 3,2 & 2,7 & 0,46 & 6,4 \\
\hline Cyathea delgadii Sternb. & 11 & 1,9 & 3,4 & 1,08 & 6,4 \\
\hline
\end{tabular}

A Tabela 9 apresenta os parâmetros fitossociológicos da área climáxica (Pico do Papagaio). Neste estágio climáxico, as 10 espécies com valores mais altos de VI (Rustia formosa, Mabea brasiliensis, Calyptranthes lucida, Vochysia bifalcata, Pradosia kulmanii, Faramea pachyantha var. mandiocana, Eclinusa ramiflora, Heisteria silvianii, Virola gardneri e Psychotria nuda) alcançaram o menor valor de todas as demais áreas $(36,3 \%$ do mesmo). Estas mesmas 10 espécies contribuíram com $32,4 \%$ da densidade de todas as espécies, com apenas $21,7 \%$ da frequiência de todas e com $55,1 \%$ da dominância de toda a área climáxica. Com relação ao grupo das 10 espécies com maior VI do estágio anterior (50 anos), nenhuma das espécies se repetiu. $\mathrm{Na}$ área climáxica do Pico do Papagaio, observou-se a tendência das espécies terem a sua importância individual reduzida, verificada também em outras áreas conservadas. Kurtz \& Araújo (2000) encontraram um valor muito próximo ao deste trabalho em relação ao somatório das mesmas 10 espécies: 35,4\% do VI total. Guedes-Bruni et al. (1997), em área conservada em Macaé de Cima, encontraram o percentual de $39,4 \%$ para as mesmas espécies em relação ao VI total, e Rodrigues (1996) encontrou valor praticamente idêntico a este $(39,1 \%)$ na Reserva Biológica do Tinguá. É característica de sistemas maduros uma alta diversidade e baixo número de indivíduos (Kurtz \& Araújo, 2000). Na média geral, foram encontrados 3,8 indivíduos por espécie, conforme a Tabela 5 .

A figura 4 apresenta os valores percentuais da distribuição dos grupos ecológicos das 10 espécies que obtiveram maiores valores de VI. A área de 5 anos tem $90 \%$ das espécies que compõem as de 10 maiores VI como pioneiras e uma única como secundária inicial. Para estas mesmas 10 espécies, na área de 25 anos, foram encontradas $20 \%$ como pioneiras, $10 \%$ como secundárias iniciais e $70 \%$ como secundárias tardias. $\mathrm{Na}$ área de 50 anos, a composição percentual das pioneiras das 10 espécies com maior VI foi idêntica à de 25 anos, tendo ocorrido uma única espécie 
Tabela 9 - Ordenação das 10 espécies da área climáxica com maior valor de importância $(\mathrm{n}=\mathrm{n}$. de indivíduos; DR = densidade relativa; $\mathrm{FR}=$ freqüência relativa; $\mathrm{DoR}=$ dominância relativa e VI = valor de importância)

\begin{tabular}{llllll}
\hline nome & N & Dr & FR & DoR & VI \\
\hline Rustia formosa (Cham. \& Schlecht.) Kl. & 31 & 6,0 & 4,28 & 13,82 & 24,1 \\
Mabea brasiliensis Muell. Arg. & 35 & 6,7 & 4,01 & 8,628 & 19,4 \\
Calyptranthes lucida Mart. & 53 & 10,2 & 3,48 & 2,627 & 16,3 \\
Vochysia bifalcata Warm. & 4 & 0,8 & 0,80 & 9,569 & 11,1 \\
Pradosia kulmannii Toledo & 3 & 0,6 & 0,80 & 8,317 & 9,7 \\
Faramea pachyantha var. mandiocana & 11 & 2,1 & 2,67 & 2,307 & 7,1 \\
$\quad$ Muel. Arg.) Muel. Arg. & & & & & \\
Ecclinusa ramiflora Mart. & 5 & 1,0 & 1,07 & 3,804 & 5,8 \\
Heisteria silvianii Schwacke & 10 & 1,9 & 2,41 & 1,123 & 5,5 \\
Virola gardneri (A. DC.) Warb. & 1 & 0,2 & 0,27 & 4,753 & 5,2 \\
Psychotria nuda Wawra & 15 & 2,9 & 1,87 & 0,145 & 4,9 \\
\hline
\end{tabular}

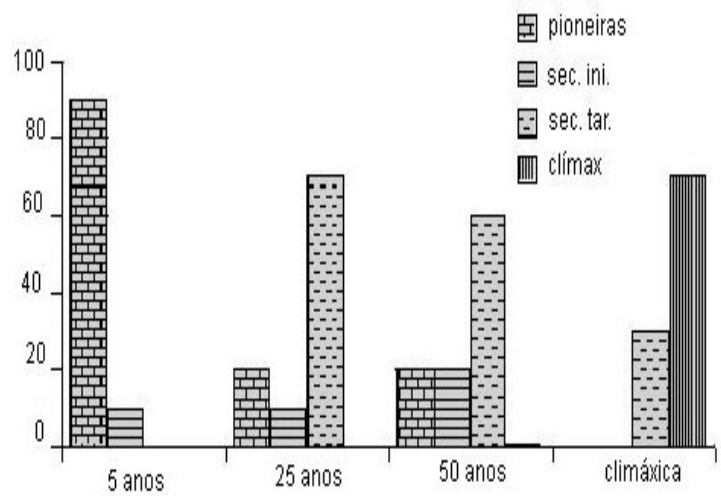

Figura 4 - Valores percentuais da participação das 10 espécies que obtiveram maiores valores de VI (Valor de Importância) nos grupos ecológicos, nas quatro áreas de estudo (pi = pioneira; $\mathrm{si}$ = secundária inicial; $\mathrm{st}$ = secundária tardia e cl = climáxica).

climáxica. No entanto, ao contrário do que seria de se esperar, a área de 50 anos apresentou um percentual maior de secundárias inicias $(60 \%) \mathrm{e}$ menor de secundárias tardias (10\%). Ou seja, aparentemente o conjunto das espécies secundárias iniciais está ocupando um papel de maior destaque na área de 50 anos do que na de 25 anos e as secundárias tardias apresentam maior relevância na área de 25 anos do que na área de 50 anos. Já na área do Pico do Papagaio, a participação das climáxicas foi de $70 \%$ e das secundárias tardias de $30 \%$.
A figura 5 apresenta a participação das 10 espécies com maior VI nos diversos parâmetros fitossociológicos da comunidade. A participação destas espécies no VI total, na densidade, na freqüência e na dominância tende a reduzir, no sentido 5 anos > clímax. No entanto, para estas quatro variáveis, a área de 25 anos apresentou valores menores do que a de 50 anos.

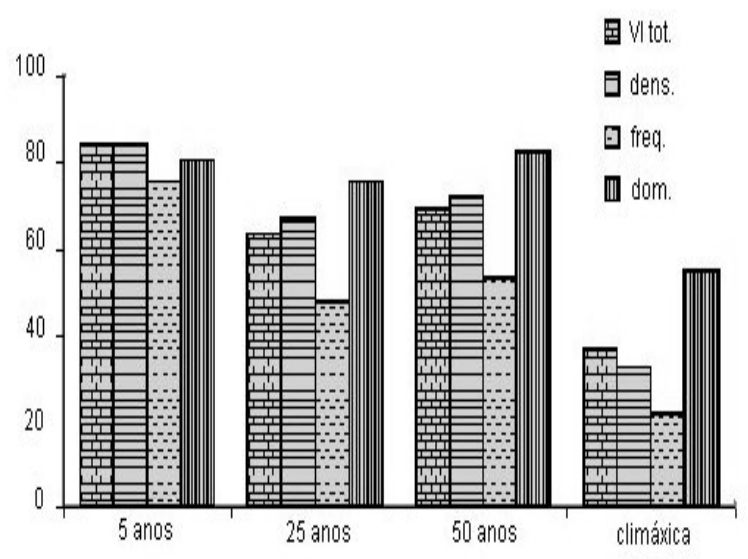

Figura 5 - Valores percentuais da participação das 10 espécies que obtiveram maiores valores de VI (Valor de Importância) em parâmetros fitossociológicas nas quatro áreas de estudo (VI tot. = participação no VI total; dens. = densidade; freq. = freqüência; dom. = dominância). 
Nas duas figuras acima, evidencia-se uma certa falta de previsibilidade em relação ao que se esperaria no curso da sucessão ecológica em aspectos ligados aos grupos ecológicos ou aos parâmetros fitossociológicos. Isto sugere que a sucessão na área de 25 anos não está aparentemente caminhando para a composição da vegetação manifestada na área de 50 anos. Neste ponto, coloca-se uma questão relevante: as quatro áreas de estudo podem ser consideradas etapas de um previsível gradiente sucessional? No que se refere às espécies exclusivas, aos grupos ecológicos de todas as espécies, às espécies raras, à área basal, aos diâmetros e alturas (tanto médios como absolutos e, ainda, aos seus respectivos coeficientes de variação), ao número de troncos múltiplos e à taxa de mortalidade, a resposta é positiva. Ou seja, estes valores aumentam (ou decrescem, conforme o caso) dentro de um claro e previsível gradiente. Já para a densidade de indivíduos, para o número de espécies (e os parâmetros daí decorrentes: densidade de espécies, número de famílias e diversidade) e, ainda, para a participação das espécies com maior VI em variáveis fitossociológicas, a resposta é negativa. Nestes casos, a tendência que se observa entre as áreas de 5 anos e 25 e 50 anos e climáxica - quase sempre assumindo um gradiente - é interrompida na passagem das áreas de 25 para 50 anos. Praticamente em todas as variáveis estudadas onde esta tendência se deu, o rompimento do padrão de gradiente ocorreu na área de 50 anos. Uma vez que o uso pretérito das 3 primeiras áreas (5, 25 e 50 anos) foi idêntico - roças caiçaras - este fato pode estar remetendo a particularidades da área de 50 anos, como solos, disponibilidade de propágulos e dispersores, taxas diferenciais de predação ou outros fatores não presentes nas demais áreas. Com relação aos solos, os valores de macro nutrientes $(\mathrm{N}, \mathrm{P}, \mathrm{K}, \mathrm{Ca}$ e $\mathrm{Mg}$ ) não apresentaram diferenças significativas entre as áreas nas profundidades de 0 a 10 $\mathrm{cm}, 10$ a $30 \mathrm{~cm}$ e 30 a $50 \mathrm{~cm}$ (Oliveira, 1999).

Outra questão a ser levantada, e relevante à análise da estrutura e composição da vegetação, é a da resultante geoecológica do manejo caiçara sobre extensões amplas de mata atlântica. Em outras palavras: com base nos dados obtidos, qual seria a influência do manejo caiçara na formação da paisagem florestada? Tomando-se como limite e escala a extensão da Ilha Grande, há que se ressaltar que não se dispõe de imagem geoprocessada que permita espacializar o grande mosaico constituído pelas manchas de florestas secundárias de diferentes idades, face às sutilezas das variações. Mesmo com a utilização de aerofotogrametria, a delimitação dos estágios sucessionais é dificultada pela inexistência de padrões que diferenciem cada estágio, notadamente para os mais avançados. No entanto, as informações obtidas em extensas explorações de campo permitem afirmar que a maior parte do território da Ilha Grande é constituído por grandes extensões de formações secundárias, a maioria em estágios avançados de regeneração, cujas idades podem estar na faixa de 30 a 100 anos.

Como foi visto anteriormente, a dinâmica de recuperação das áreas de estudos de 25 anos e 50 anos em parâmetros ligados à composição da vegetação é bastante lenta em relação à situação encontrada na área climáxica. $\mathrm{O}$ exame da Tabela 4 e das figuras 4 e 5 sugere que as áreas de 25 e de 50 anos apresentam um comportamento muito lento na evolução destes parâmetros, em relação à situação dos mesmos observada na área climáxica. Segundo Sastre (1982), a evolução muito lenta de formações secundárias com uma estrutura e cortejo florístico particulares caracteriza o chamado clímax antrópico ou antropogênico. Aceitando-se esta definição, o estabelecimento de um clímax antrópico parece ser a principal marca na estrutura e composição da vegetação que a atividade agrícola dos caiçaras (e dos grupamentos indígenas que os precederam) deixou sobre a paisagem florestada e que deve permanecer longo tempo após o término da intervenção do homem sobre o meio. 


\section{AGRADECIMENTOS:}

O autor deseja expressar sinceros agradecimentos a Inês Machline Silva, André Scarambone Zaú, Rogerio Ferreira da Silva, Carlos Alberto Leal de Oliveira, Antônio Cardoso de Souza, Patrícia Delamônica e Denise Flores Lima, sem os quais este trabalho não poderia ter sido realizado. E também aos botânicos Ariane Luna Peixoto, Bruno C. Kurtz, Claudia Vieira Magalhães, Dorothy Sue Dunn de Araújo, Haroldo Cavalcanti de Lima, Jorge Pedro, P. Carauta, João Marcelo Braga, Maria Celia Vianna, Mário Gomes e Ronaldo Marquette, pela determinação do material botânico.

\section{REFERÊNCIAS BIBLIOGRÁFICAS}

Adams, C. 2000. Caiçaras na Mata Atlântica: pesquisa científica versus planejamento e gestão ambiental. São Paulo, Ed. Amablume/ FAPESP. 337 p.

Baider, C., Tabarelli, M. \& Mantovani, W. 2001. The soil seed bank during atlantic forest regeneration in southeast Brazil. Rev. Brasil. Biol. 61(1):35-44.

Budowski, G. 1965. Distribution of tropical American Rain Forest trees in the light of successional process. Turrialba 15 : 40-45.

Clark, D.B. 1996. Abolishing virginity. Journal of Tropical Ecoloy 12:435-439.

Clements, F.E. 1916. Plant succession: An analysis of the development of vegetation. Washington, Carnegie Inst. \& Whashington Publ. 242 p.

Connel, J.H. 1978. Diversity in tropical rain forest s and coral reefs. Science, 199: 1302-1310.

Costa, L.G.S., Mantovani, W. 1995. Dinâmica sucessional da floresta mesófila semidecídua em Piracicaba (SP). Oecologia Brasiliensis 1:291-305.

Crow, T.R. 1980. A rainforest chronicle: a 30 year record of change in structure and composition at El Verde, Puerto Rico. Biotropica 12(1):54-55.
Delamonica, P.S. 1997. Florística e estrutura de floresta atlântica secundária - Reserva Biológica Estadual da Praia do Sul, Ilha Grande, RJ. São Paulo, Dissertação de Mestrado, IB/USP, 178 p.

Ewel, J.J. 1976. Litter fall and leaf decompostion in a tropical forest sucession in eastern Guatemala. J. Ecology 64:293-308.

Finegan, B. 1996. Forest Sucession. Nature 312:109-114.

Gadgil, M., Berkes, F. \& Folke, C. 1993. Indigenous knowledge for biodiversity conservation. Ambio 22(2-3):151-157.

Guedes-Bruni, R.R., Pessoa, S.V.A. \& Kurtz, B.C. 1997. Florística e estrutura do componente arbustivo-arbóreo de um trecho preservado de floresta montana na $\mathrm{Re}$ serva Ecológica de Macaé de Cima. In: Lima, H.C. \& Guedes-Bruni, R.R. (eds.) Serra de Macaé de Cima: diversidade florística e conservação em Mata Atlântica. Rio de Janeiro, Instituto Jardim Botânico do Rio de Janeiro, p. 128-145.

Hecht, S.B. \& Posey, D.A. 1989. Preliminary results on solil management techiniques of the Kayapó Indians. Advances in Economic Botany 7:174-188.

Horn, H.S. 1974. The ecology of secondary succession. Ann. Rev. of Ecol. and Syst. 5:25-37

Kurtz, B.C. \& Araújo, D.S.D. 2000. Composição florística e estrutura do componente arbóreo de um trecho de Mata Atlântica na Estação Ecológica do Paraíso, Cachoeiras do Macacú, RJ, Brasil. Rodriguesia, 51(78/115):69-112.

Leitão Filho et al.1993. Ecologia da mata atlântica em Cubatão. Campinas, Ed. UNESP, $184 \mathrm{p}$.

Magurran, A.E. 1988. Ecological diversity and its measurement. London, Croom Helm Limited, $179 \mathrm{p}$.

Mantovani, W. 1993. Estrutura e dinâmica da Floresta Atlântica na Juréia, Iguape $S P$. São Paulo, Tese de Livre-Docência, Instituto de Biociências, USP, 126 p. 
Mantovani, W. et al., 1990. A vegetação da Serra do Mar em Salesópolis. In: II Simpósio de Ecossistema da Costa Sul e Sudeste Brasileira: estrutura, função e manejo, Águas de Lindóia, Anais, v. 1, p. 348-384.

Martins, F.R. 1991. Estrutura de uma floresta mesófila. 2 ${ }^{\underline{a}}$ ed. Campinas, Ed. da UNICAMP (Série Teses), 246 p., il.

Mello, C.E.H.V. 1987. Apontamentos para a história Fluminense (Ilha Grande), Angra dos Reis. Angra dos Reis, Edição do Conselho Municipal de Cultura. $36 \mathrm{p}$.

Melo, M.M.R.F. et al. 1998. Fitossociologia de trecho de mata atlântica na planície do Rio Verde, Estação Ecológica de Juréia-Itatins, SP, Brasil. In: IV Simpósio de Ecossistema da Costa Sul e Sudeste Brasileira: estrutura, função e manejo, Águas de Lindóia, Anais, v. 1 p. 49-56.

Mueller-Dombois, D. \& Ellenberg, H. 1974. Aims and methods of vegetation ecology. New York, Ed. John Willey \& Sons, $574 \mathrm{p}$.

Odum, E.P. 1969. The strategy of ecosystem development. Science 164: 262-270.

Oliveira, R.R. 1999. O rastro do homem na floresta: sustentabilidade e funcionalidade da mata atlântica sob manejo caiçara. Rio de Janeiro, Tese de Doutorado. UFRJ/ Progr. Pós Graduação em Geografia, $150 \mathrm{p}$.

Oliveira, R.R. \& Coelho Netto, A.L. (2000). Processos interativos homem-floresta na evolução da paisagem da Ilha Grande, RJ. Rev. Dept. de Geografia UERJ.8:29-38.

Oliveira, R.R., A.S. Zaú, D.F. Lima, M.B.R. Silva, M.C. Vianna, D.O. Sodré \& P.D. Sampaio. 1995. Significado ecológico de orientação de encostas no Maciço da Tijuca, Rio de Janeiro. In: Esteves, F.A. (ed.) Oecologia Brasiliensis: estrutura, funcionamento e manejo de ecossistemas brasileiros. Rio de Janeiro, Ed. da UFRJ, v. 1, p. 523-541.
Oliveira, R.R.. D.F. Lima, P. Delamonica, R.F. Silva \& D.D.G. Toffoli. 1995. Roça caiçara: um sistema "primitivo" auto-sustentável. Ciência Hoje 18 (104): 45-51.

Peixoto, A.L. \& Gentry, A. 1990. Diversidade e composição florística da mata de tabuleiro na Reserva Florestal de Linhares (Espírito Santo, Brasil). Revta. brasil. Bot. 13: 19-25.

Pereira, T.S. 1998. Ecologia de Miconia cinnamomifolia (DC.) Naud.- jacatirão na sucessão ecológica da Mata Atlântica. São Paulo, Tese de Doutrado, IB/ USP. 178 p.

Pessoa, S.V.A., Guedes-Runi, R.R. \& Kurtz, B.C. 1997. Composição florírstica e estrutura do componente arbustivo-arbóreo de um trecho secundário de floresta montana na Reserva Ecológica de Macaé de Cima. In: Lima, H.C. \& Guedes-Bruni, R.R. (eds.) Serra de Macaé de Cima: diversidade florística e conservação em Mata Atlântica. Rio de Janeiro, Instituto Jardim Botânico do Rio de Janeiro, p. 148-167.

Rodrigues, H.C. 1996. Composição florística e fitossociologia de um trecho de mata atlântica na Reserva Biológica do Tinguá, Rio de Janeiro, RJ. Rio de Janeiro, Dissertação de Mestrado, MN/ UFRJ, $77 \mathrm{p}$.

Roizman, L.G. 1993. Fitossociologia e dinâmica do banco de sementes de populações arbóreas de floresta secundária em São Paulo, SP. São Paulo, Depto. de Ecologia Geral/ USP, 184p.

Saldarriaga, J.G. \& Uhl, C. 1991. Recovery of forest vegetation following slash-andburn agriculture in the upper Rio Negro. In: A. Gómes-Pompa, T.C. Whitmore \& M. Hadley (eds.) Rain forest regeneration and management. London, The Parthenon Publ. Group. Man and the biosfere series v. 6. p: 303-312.

Sanchez, M. et al. 1999. Composição florística de um trecho de floresta ripária na Mata Atlântica em Picinguaba, Ubatuba, SP. 
Rev. bras. Bot. 22 (1): 75-87.

Sastre, C. 1982. Notion de climax em régions néotropicales. Compte rendu des sceances de la Societé de Biogeographie, 58(3): 117:123.

Schmidt, C.B. 1958. A lavoura caiçara. Rio de Janeiro, Ministério da Agricultura, Serviço de Informação Agrária, Documento da Vida Rural n. 14. 179 p.

Silva, A.F. 1980. Composição florística e estrutura de um trecho da Mata Atlântica de encosta no Município de Ubatuba - São Paulo. São Paulo, Dissertação de Mestrado, Instituto de Biologia/ UNICAMP, $152 \mathrm{p}$.

Silva, R.F. 1998. Roça caiçara: dinâmica de nutrientes, propriedades físicas e fauna do solo em um ciclo de cultura. Seropédica, Dissertação de Mestrado, Dept. de Solos, UFRRJ,. 164 p.

Tenório, M.C. 1999. Os fabricantes de machado da Ilha Grande. In: Tenório, M.C. (org.) Pré-história da Terra Brasilis. Rio de Janeiro, Ed. da UFRJ. p. 231-246.

Tofffoli, D.D. \& Oliveira, R.R. 1999. Caiçara Agroforestry Manegement. In: Posey, D.A. (org.): Cultural and spiritual values of biodiversity. Nairobi, United Nations Environment Program, Intermediate Tecnology Publications. p. 302-305.

Torezan, J.M.D. 1995. Estudo da Sucessão secundária na Floresta Ombrófila Densa Submontana, em áreas anteriormente cultivadas pelo sistema de "coivara”, em Iporanga, SP. Curitiba, Dissertação de Mestrado, Departamento de Botânica/UFP. 89 p.

Uhl, C; Buschbacher, R., Serrão, E.A.S. 1988. Abandoned pastures in eastern Amazonia. I. Patterns of plant succession. J. Ecol. 76: 663-681.

Veloso, H.P., Rangel-Filho, A.L.R. \& Lima, J.C.A. 1991. Classificação da vegetação brasileira, adaptada a um sistema universal. Rio de Janeiro, IBGE, Departamento de Recursos Naturais e Estudos
Ambientais, $124 \mathrm{p}$.

Whitmore, T.C. 1984. An introduction to tropical rain forests. Oxford, Claredon Press, $224 \mathrm{p}$.

Zaú, A.S. 1994. Cobertura vegetal: transformações e resultantes microclimáticas e hidráulico-superficiais na vertente norte do Morro do Sumaré, Parque Nacional da Tijuca, RJ. Rio de Janeiro, Dissertação de Mestrado, PPGG/ UFRJ, 132 p. 